NASA/TM-2013-216554

\title{
Aerodynamic Characterization of a Thin, High-Performance Airfoil for Use in Ground Fluids Testing
}

Andy P. Broeren

Glenn Research Center, Cleveland, Ohio

Sam Lee

Vantage Partners, LLC, Brook Park, Ohio

Catherine Clark

National Research Council Canada, Ottawa, Ontario, Canada 


\section{NASA STI Program . . . in Profile}

Since its founding, NASA has been dedicated to the advancement of aeronautics and space science. The NASA Scientific and Technical Information (STI) program plays a key part in helping NASA maintain this important role.

The NASA STI Program operates under the auspices of the Agency Chief Information Officer. It collects, organizes, provides for archiving, and disseminates NASA's STI. The NASA STI program provides access to the NASA Aeronautics and Space Database and its public interface, the NASA Technical Reports Server, thus providing one of the largest collections of aeronautical and space science STI in the world. Results are published in both non-NASA channels and by NASA in the NASA STI Report Series, which includes the following report types:

- TECHNICAL PUBLICATION. Reports of completed research or a major significant phase of research that present the results of NASA programs and include extensive data or theoretical analysis. Includes compilations of significant scientific and technical data and information deemed to be of continuing reference value. NASA counterpart of peer-reviewed formal professional papers but has less stringent limitations on manuscript length and extent of graphic presentations.

- TECHNICAL MEMORANDUM. Scientific and technical findings that are preliminary or of specialized interest, e.g., quick release reports, working papers, and bibliographies that contain minimal annotation. Does not contain extensive analysis.

- CONTRACTOR REPORT. Scientific and technical findings by NASA-sponsored contractors and grantees.
- CONFERENCE PUBLICATION. Collected papers from scientific and technical conferences, symposia, seminars, or other meetings sponsored or cosponsored by NASA.

- SPECIAL PUBLICATION. Scientific, technical, or historical information from NASA programs, projects, and missions, often concerned with subjects having substantial public interest.

- TECHNICAL TRANSLATION. Englishlanguage translations of foreign scientific and technical material pertinent to NASA's mission.

Specialized services also include creating custom thesauri, building customized databases, organizing and publishing research results.

For more information about the NASA STI program, see the following:

- Access the NASA STI program home page at http://www.sti.nasa.gov

- E-mail your question to help@sti.nasa.gov

- Fax your question to the NASA STI Information Desk at 443-757-5803

- Phone the NASA STI Information Desk at 443-757-5802

- Write to: STI Information Desk NASA Center for AeroSpace Information 7115 Standard Drive Hanover, MD 21076-1320 
NASA/TM-2013-216554

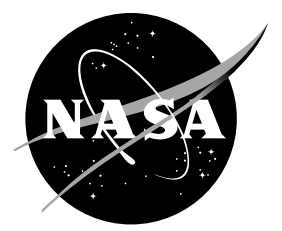

\section{Aerodynamic Characterization of a Thin, High-Performance Airfoil for Use in Ground Fluids Testing}

Andy P. Broeren

Glenn Research Center, Cleveland, Ohio

Sam Lee

Vantage Partners, LLC, Brook Park, Ohio

Catherine Clark

National Research Council Canada, Ottawa, Ontario, Canada

Prepared for the

5th Atmospheric and Space Environments Conference

sponsored by the American Institute of Aeronautics and Astronautics

San Diego, California, June 24-27, 2013

National Aeronautics and

Space Administration

Glenn Research Center

Cleveland, Ohio 44135 


\section{Acknowledgments}

The authors wish to acknowledge the contributions to this paper from other members of the research team. Warren Underwood of the FAA, John D'Avirro and Marco Ruggi of APS Aviation provided invaluable insights into the characteristics of the antiicing fluids testing and results. They also dedicated significant effort to fluid tests supporting this work including the secondary wave investigations. The authors also appreciate the contributions of the engineering and technician staff at the NRC Propulsion and Icing Wind Tunnel. Lloyd Utt at NASA Glenn Research Center (GRC) deserves recognition for his assistance preparing the figures in this paper. Gene Addy and Mary Wadel of GRC provided additional technical and management review. The support of these individuals is gratefully acknowledged. The NASA Aviation Safety Program, Atmospheric Environment Safety Technologies Project and the FAA Ground Icing Program also supported this work.

Trade names and trademarks are used in this report for identification only. Their usage does not constitute an official endorsement, either expressed or implied, by the National Aeronautics and Space Administration.

Level of Review: This material has been technically reviewed by technical management.

Available from

NASA Center for Aerospace Information 7115 Standard Drive

Hanover, MD 21076-1320
National Technical Information Service 5301 Shawnee Road Alexandria, VA 22312 


\title{
Aerodynamic Characterization of a Thin, High-Performance Airfoil for Use in Ground Fluids Testing
}

\author{
Andy P. Broeren \\ National Aeronautics and Space Administration \\ Glenn Research Center \\ Cleveland, Ohio 44135 \\ Sam Lee \\ Vantage Partners, LLC \\ Brook Park, Ohio 44142 \\ Catherine Clark \\ National Research Council Canada \\ Ottawa, Ontario K1A 0R6 Canada
}

\begin{abstract}
The FAA has worked with Transport Canada and others to develop allowance times for aircraft operating in ice-pellet precipitation. Wind-tunnel testing has been carried out to better understand the flowoff characteristics and resulting aerodynamic effects of anti-icing fluids contaminated with ice pellets using a thin, high-performance wing section at the National Research Council of Canada Propulsion and Icing Wind Tunnel. The objective of this paper is to characterize the aerodynamic behavior of this wing section in order to better understand the adverse aerodynamic effects of anti-icing fluids and ice-pellet contamination. Aerodynamic performance data, boundary-layer surveys and flow visualization were conducted at a Reynolds number of approximately $6.0 \times 10^{6}$ and a Mach number of 0.12 . The clean, baseline model exhibited leading-edge stall characteristics including a leading-edge laminar separation bubble and minimal or no separation on the trailing edge of the main element or flap. These results were consistent with expected 2-D aerodynamics and showed no anomalies that could adversely affect the evaluation of anti-icing fluids and ice-pellet contamination on the wing. Tests conducted with roughness and leading-edge flow disturbances helped to explain the aerodynamic impact of the anti-icing fluids and contamination. The stalling characteristics of the wing section with fluid and contamination appear to be driven at least partially by the effects of a secondary wave of fluid that forms near the leading edge as the wing is rotated in the simulated takeoff profile. These results have provided a much more complete understanding of the adverse aerodynamic effects of anti-icing fluids and ice-pellet contamination on this wing section. This is important since these results are used, in part, to develop the ice-pellet allowance times that are applicable to many different airplanes.
\end{abstract}

\section{Nomenclature}

$b \quad$ model span

$c \quad$ chord length

$k$ roughness or disturbance height

$u \quad$ mean streamwise velocity

$x \quad$ chordwise wing coordinate

$y \quad$ spanwise wing coordinate

$z \quad$ vertical wing coordinate

$z$ ' wall-normal coordinate

$C_{D} \quad$ wing drag coefficient 


$\begin{array}{ll}C_{L} & \text { wing lift coefficient } \\ C_{M} & \text { wing quarter-chord pitching moment } \\ C_{L, \text { max }} & \text { maximum lift coefficient } \\ H & \text { boundary-layer shape factor } \\ U_{\text {edge }} & \text { boundary-layer edge velocity } \\ U_{\infty} & \text { freestream velocity } \\ \alpha & \text { angle of attack } \\ \alpha_{\text {stall }} & \text { stalling angle of attack, coincident with } C_{L, \max } \\ \delta & \text { boundary-layer thickness } \\ \delta^{*} & \text { boundary-layer displacement thickness } \\ \theta & \text { boundary-layer momentum thickness } \\ \text { AAT } & \text { Aerodynamic Acceptance Test } \\ \text { FAA } & \text { Federal Aviation Administration } \\ \text { HOT } & \text { Holdover Time } \\ \text { IRT } & \text { Icing Research Tunnel } \\ \text { NASA } & \text { National Aeronautics and Space Administration } \\ \text { NRC } & \text { National Research Council (Canada) } \\ \text { PIWT } & \text { Propulsion and Icing Wind Tunnel }\end{array}$

\subsection{Introduction}

The proper use of deicing and anti-icing fluids is required to maintain adequate safety margins for takeoffs in cold-weather-precipitation conditions. The FAA and other civil airworthiness authorities publish holdover time tables (HOTs) that determine, in part, the length of time airplanes may remain on the ground after treatment with deicing and anti-icing fluids depending upon the weather conditions. HOTs are determined based on the results of endurance time testing of ground fluids in natural or simulated icing conditions. The endurance times are determined by applying failure criteria using visual cues, which vary depending on the weather conditions (snow, freezing drizzle, freezing rain). While HOTs exist for most types of weather conditions, ice-pellet precipitation and ice-pellets mixed with other types of precipitation (Ref. 1) have demonstrated different behaviors. The difficulty in establishing visual cues for detecting fluid failure in ice-pellet conditions has thus far precluded the establishment of practical failure criteria for endurance time testing. The FAA has never provided HOTs for operations in ice-pellet conditions since HOTs cannot be established without endurance time testing.

In 2005, the FAA became concerned about operations in ice-pellet conditions after learning of questions raised relating to regional carriers operating in ice pellets with non-slatted aircraft and with less experienced flight crews than the major carriers. As a result of these concerns, the FAA issued three notices effectively disallowing operations in ice pellets in October 2005 (Refs. 2 to 4 . In the winter of 2005-2006, this action had a major impact at several airports during ice-pellet events. Due in part to concerns raised by these events, the FAA undertook a thorough reassessment of its policy with respect to operation in ice-pellet conditions. Environmental chamber testing also raised questions regarding the ability of the anti-icing fluid to flow off aerodynamic surfaces during a takeoff run. Adhering contamination or a significant amount of fluid remaining on the wing at takeoff would both present a safety hazard.

The significant differences in ice-pellet precipitation behavior relative to other forms of precipitation combined with the potential flight safety hazards led the FAA Ground Icing Program and Transport Canada to sponsor aircraft-based and wind-tunnel based research to better determine allowance times associated with operations in ice-pellet conditions. An allowance time differs from a HOT in that there is no provision for a pre-takeoff contamination check if the time is exceeded, meaning that the allowance 
time cannot be extended by visual or external tactile checks of the aircraft critical surfaces within 5 min of takeoff. Ordinarily pre-takeoff contamination checks are conducted from the cabin, and the research showed that such a check would be of little use in the case of ice pellets (Ref. 5). Broeren and Riley (Refs. 6 and 7) provide a more detailed summary of this flight-based and wind-tunnel based research along with a description of the resulting ice-pellet allowance time tables (Refs. 8 to 10). Of interest here is the evolution of the wind-tunnel experiments and resulting safety implications.

A series of test campaigns were conducted beginning in January 2007 through February 2012 at the Propulsion and Icing Wind Tunnel (PIWT) owned and operated by the National Research Council (NRC) of Canada (Refs. 11 and 12). Ice pellets were simulated using crushed ice from blenders which was run through sieves yielding a size distribution similar to natural ice pellets. An airplane takeoff acceleration profile and rotation were simulated in the wind-tunnel testing. Initially, allowance times were determined using the visual observations of the researchers and existing single-element airfoil models were used for testing. Beginning in January-February 2010, tests were continued in the NRC PIWT using a thin, highperformance wing section rigged with a single-element slotted flap fixed at $20^{\circ}$. The thin, highperformance airfoil was regarded as typical of wings on regional jet transport airplanes. Aerodynamic measurements were again made, and effects on lift coefficient were significantly larger than in past years. Along with visual evaluation by the researchers, a criterion for percentage loss in lift at $8^{\circ}$ angle of attack was explicitly used in developing allowance times. Based on the results, the FAA published an updated ice-pellet allowance time table for winter 2010-2011 and 2011-2012 (Ref. 13).

The introduction of an aerodynamic-performance based criterion and subsequent changes to the icepellet allowance time tables led to concerns regarding the fidelity and applicability of the measured lift degradation in the ice-pellet contamination fluid testing at the NRC PIWT. Given the potential operational safety implications associated with the measured performance degradations, it is even more important that these concerns be addressed appropriately. The essence of these concerns is understanding how the performance degradations measured on the 2-D model in the NRC PIWT testing relate to an actual 3-D, full-scale airplane configuration. Broeren and Riley (Refs. 6 and 7) developed a scaling method based upon the Aerodynamic Acceptance Test (AAT) that scaled the percent lift loss on the thinhigh performance wing to the percent loss in maximum lift on a full-scale Boeing 737-200ADV airplane. This scaling relationship allowed the aerodynamic performance penalty to be used as one of several criteria in determining allowance times for ice-pellet precipitation conditions.

Broeren and Riley (Refs. 6 and 7) also addressed a number of concerns regarding the aerodynamic testing conducted at PIWT. These issues were related to the design and conduct of the experiments relative to standard aerodynamic test methodology. While this review showed that the tests were conducted in accordance with commonly accepted practices, no baseline aerodynamic characterization of the thin, high-performance wing section had been conducted. Due to the unique design of the model and lack of any comparable data, such a characterization was recommended in order to better understand the airfoil aerodynamic behavior. Research of this type had been carried out by Hill and Zierten et al. (Refs. 14 and 17) in their development of the AAT that is used to qualify deicing and anti-icing fluids (Ref. 18) The authors used both 2-D and 3-D models and conducted extensive flow visualization studies on the clean, dry models as well as aerodynamic performance studies with roughness and simulated frost applied to the models. Data from the latter experiments were used to help explain the adverse performance effects observed during the fluid tests and relate these adverse effects to those observed on larger-scale models. A similar approach was followed in the present research using the thin, highperformance wing. The present research was necessary because the design of the thin, high-performance wing is significantly different from airfoils and wings used in past research. Furthermore, previous work was conducted before the advent of Type IV anti-icing fluids used in the present research along with the additional effects of ice-pellet contamination. These factors required additional research into the aerodynamic effects of the fluids and contamination.

The objective of the present research was to characterize the aerodynamic behavior of the thin, highperformance wing used for aerodynamic testing of ground anti-icing fluids. Aerodynamic performance measurements, flow visualization and boundary-layer surveys were conducted on the clean, dry wing. 
Tests were performed with leading-edge roughness (simulating ice roughness) and roughness applied to the entire upper surface (simulating frost). Additional tests were conducted to simulate the specific effects of the transitory nature of the anti-icing fluids. This characterization is important to understand the adverse aerodynamic effects of anti-icing fluids and ice-pellet contamination on this model since the results are used, in part, to develop ice-pellet allowance times that are applicable to many different airplanes.

\subsection{Experimental Methods}

All of the experiments were carried out using the thin, high-performance wing section in the NRC PIWT facility located on the Montreal Road campus in Ottawa. The PIWT is an open-return wind tunnel that draws air from the outdoors and is therefore naturally cooled. The fan is located in the wind-tunnel inlet and was driven by a gas turbine engine for the test campaign. The test section measures $10 \mathrm{ft}(3 \mathrm{~m})$ across and $20 \mathrm{ft}(6 \mathrm{~m})$ in height. An insert was used that reduced the height to $16.4 \mathrm{ft}(5 \mathrm{~m})$ resulting in an increase in maximum test-section speed. The wing was mounted horizontally in the test section as shown in Figure 1. The model had a span of $7.9 \mathrm{ft}(2.4 \mathrm{~m})$ and was isolated from the wind-tunnel walls with endplates. There were large gaps between the endplates and the test-section walls $(\approx 1 \mathrm{ft}(0.3 \mathrm{~m})$ on each side). The size of the endplates was minimized to facilitate visual access to the wing surface which was very important for the experiments with anti-icing fluids and contamination. An additional motivation of this work was to determine any adverse effect of these gaps coupled with the relatively small size of the endplates. Figure 2 shows the $6 \mathrm{ft}(1.8 \mathrm{~m})$ chord, thin, high-performance wing section with a singleslotted flap deflected at $20^{\circ}$. The model had a fixed (or "hard") leading edge and the airfoil design was regarded as representative of wings on regional jet transport airplanes.
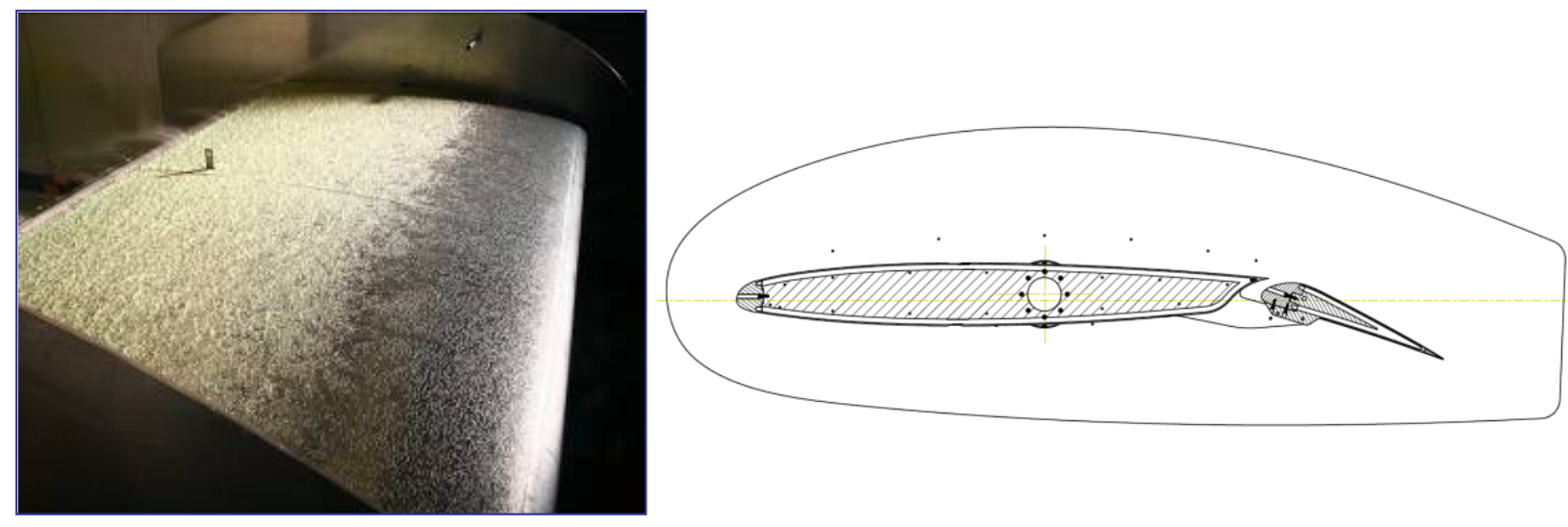

Figure 1.-Photograph of thin, high-performance wing section installed in the NRC PIWT facility and end-view drawing of endplate configuration.

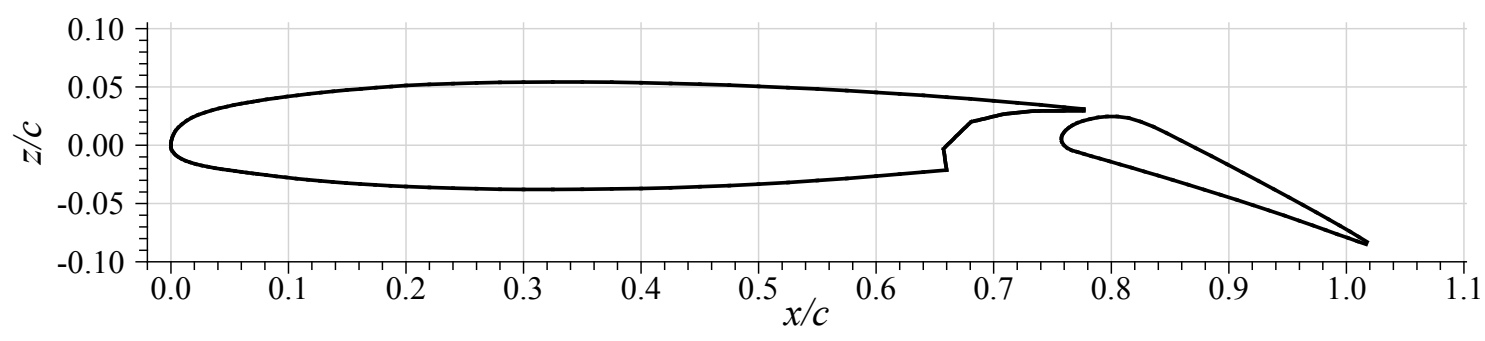

Figure 2.-Thin, high-performance airfoil section used in the PIWT testing, reference chord $=6.0 \mathrm{ft}(1.82 \mathrm{~m})$. 
The model was supported by two-component external force balances at each end, located outside of the test-section walls. Each balance rotated with the wing section, and consisted of two load cells in the normal direction and one load cell in the axial direction. A drive motor and gearbox connected to the leftside force balance provided rotation for setting the wing geometric pitch angle. Lift, drag and pitching moment data were measured from the balance during angle of attack sweeps. These data were corrected for wind-tunnel wall effects using the 2-D airfoil methods described in Rae and Pope (Ref. 19) Performance data were acquired over a small range of Reynolds and Mach number depending upon the outside air temperature and the speed. These conditions are summarized in Table 1. This experimental set-up is very similar to that used to evaluate the performance of fluids in their uncontaminated state and with ice-pellet contamination and has been described elsewhere (Refs. 20 and 21).

A detailed uncertainty analysis was performed for the aerodynamic data for 20:1 odds. The combined non-linearity and repeatability for each load cell in the balance is \pm 0.11 percent of the rated output. This results in an uncertainty of $\pm 4.47 \mathrm{lbf}( \pm 19.9 \mathrm{~N})$ in the total normal force and $\pm 1.25 \mathrm{lbf}( \pm 5.6 \mathrm{~N})$ in the total axial force. The uncertainty associated with the pitching moment about the balance center is $\pm 6.13 \mathrm{lbf}-\mathrm{ft}$ $( \pm 8.31 \mathrm{Nm})$. The dynamic pressure in the test section was calculated based on a pre-defined calibration constant and the measured dynamic pressure in the wind-tunnel contraction. The contraction dynamic pressure has a combined precision and accuracy of $\pm 4.38 \times 10^{-5} \mathrm{psi}( \pm 0.302 \mathrm{~Pa})$ that corresponds to an uncertainty in the test section dynamic pressure of \pm 0.0419 percent at $80 \mathrm{kn}$ and \pm 0.0283 percent at $100 \mathrm{kn}$. The combined uncertainties of the balance loads and the test-section dynamic pressure were used to calculate the instrumentation error associated with each of the aerodynamic coefficients as a function of the test-section velocity and the wing geometric pitch angle. The uncertainty associated with the geometric pitch angle is based on the accuracy of the inclinometer used to set the wing pitch angle and the backlash in the gear box system that drives the wing rotation. In addition to instrumentation error, the repeatability of each measurement point was considered in the evaluation of the overall data uncertainty. For the clean-wing cases, the standard deviation of the aerodynamic coefficients at each angle of attack was calculated from numerous repeat runs conducted throughout the test campaign. The instrumentation errors and the standard deviations of the clean wing measurements were combined to provide the total uncertainties associated with the lift, drag and pitching moment coefficients. The average of the total uncertainties for $-2^{\circ} \leq \alpha \leq 21^{\circ}$ are shown in Table 2 . All of these uncertainties were considered acceptable given the objectives of this research.

TABLE 1.-REYNOLDS AND MACH NUMBER CONDITIONS

\begin{tabular}{|c|c|c|c|}
\hline $\begin{array}{c}\text { Speed, } \\
\mathrm{kn}\end{array}$ & $\begin{array}{c}\text { Temperature, } \\
{ }^{\circ} \mathrm{C}\end{array}$ & $\begin{array}{c}\text { Reynolds } \\
\text { Number }\end{array}$ & $\begin{array}{c}\text { Mach } \\
\text { Number }\end{array}$ \\
\hline 80 & 0 & $5.6 \times 10^{6}$ & 0.12 \\
80 & -20 & $6.5 \times 10^{6}$ & 0.13 \\
100 & 0 & $7.0 \times 10^{6}$ & 0.16 \\
100 & -20 & $8.1 \times 10^{6}$ & 0.16 \\
\hline
\end{tabular}

TABLE 2.-SUMMARY OF AERODYNAMIC PERFORMANCE UNCERTAINTY

\begin{tabular}{|c|c|c|}
\hline Quantity & $\begin{array}{c}\text { Total uncertainty } \\
\text { at } 80 \mathrm{kn}\end{array}$ & $\begin{array}{c}\text { Total uncertainty } \\
\text { at } 100 \mathrm{kn}\end{array}$ \\
\hline$C_{L}$ & \pm 0.012 & \pm 0.011 \\
$C_{D}$ & \pm 0.004 & \pm 0.004 \\
$C_{M}$ & \pm 0.002 & \pm 0.002 \\
\hline
\end{tabular}


Aerodynamic performance data from the force balance were supported by flow visualization and boundary-layer measurements. Flow visualization was conducted using thread tufts and surface oil in separate experiments. Tufts were applied across the span of the model in several chordwise rows on the main element and flap. The tufts provided some information about the unsteady characteristics of the flow as the airfoil model was pitched through stall. The surface oil flow visualization provided a higherresolution, but time-averaged, view of the boundary-layer state on the model upper surface. Standard grade mineral oil was dyed with black carbon powder and applied to the model with a paint roller. The bare aluminum surface of the model was covered with a smooth, self-adhesive, plastic film to provide a uniform background. After the oil was applied, the angle of attack and tunnel speed were set to the desired values. Steady state was achieved after a few minutes of run time and was confirmed by visual observation through the test-section windows. Photographs were taken at the end of each run.

The boundary-layer velocity profiles were measured using a rake with 21 total pressure tubes as shown in Figure 3. This rake also contained a single tube used to measure the local static pressure that was used to compute the mean streamwise velocity from the total pressures. The rake was placed at three spanwise locations near the trailing edge of the main element. These locations were near the midspan station and approximately $2 \mathrm{ft}(0.6 \mathrm{~m})$ to the right and left of the midspan station $(y / b= \pm 0.25)$. Boundarylayer profiles were also measured near the trailing edge of the flap at the midspan station. The mean streamwise velocity profiles were subsequently integrated to obtain the boundary-layer displacement thickness, momentum thickness and shape factor using the following equations for incompressible flow:

$$
\begin{gathered}
\delta^{*}=\int_{0}^{\delta}\left(1-\frac{u}{U_{\text {egde }}}\right) d z^{\prime} \\
\theta=\int_{0}^{\delta} \frac{u}{U_{\text {egde }}}\left(1-\frac{u}{U_{\text {egde }}}\right) d z^{\prime} \\
H=\frac{\delta^{*}}{\theta}
\end{gathered}
$$

The boundary-layer pressures were measured using a ZOC 33 module that had a 1-psid (6,895 Pa) range and an accuracy of $\pm 0.001 \mathrm{psi}( \pm 6.9 \mathrm{~Pa})$. The resulting uncertainties in typical boundary-layer velocities ranged from \pm 1.21 percent for those closest to the wing surface to \pm 0.32 percent for those at the boundary-layer edge - assuming a freestream speed of $100 \mathrm{kn}$.
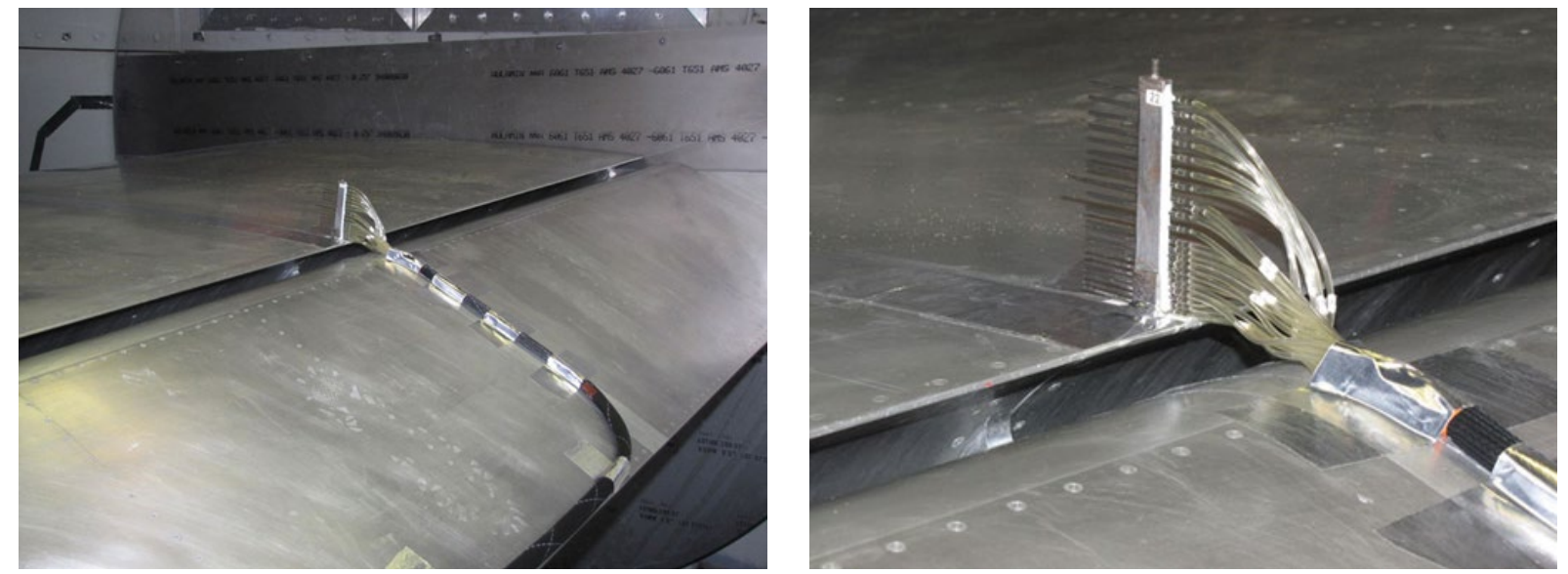

Figure 3.-Pressure rake used to measure boundary-layer velocity profiles shown at midspan station near trailing edge of main element. 
A number of experiments were conducted with simulated leading-edge ice roughness and uppersurface frost. These sources of environmental contamination were simulated with sandpaper roughness of various grit size as listed in Table 3. Three roughness sizes representing initial ice accretion were applied to the leading edge from $x / c=0.08$ on the lower surface to $x / c=0.05$ on the upper surface. The $k / c=$ 0.00010 roughness representing frost was applied over the entire upper surface starting at $x / c=0.08$ on the lower surface. Following the method in Runyan et al. (Ref. 17), the $k / c=0.00010$ roughness was systematically removed from the leading edge toward the trailing edge. This provided an approximate simulation of the aerodynamic effect of the anti-icing fluid as it flowed off of the airfoil model. Other tests were performed with roughness applied to the flap only. The effect of leading-edge disturbances was also investigated using layers of aluminum speed tape applied across the span of the model near the leading edge. Table 4 summarizes the disturbance heights that were investigated.

TABLE 3.-SANDPAPER ROUGHNESS SIZES

\begin{tabular}{|c|c|c|}
\hline Grit size & $\begin{array}{c}\text { Roughness height, } k, \\
\text { in. }(\mathrm{mm})\end{array}$ & $k / c$ \\
\hline 40 & $0.0166(0.42)$ & 0.00023 \\
80 & $0.0072(0.18)$ & 0.00010 \\
150 & $0.0036(0.09)$ & 0.00005 \\
\hline
\end{tabular}

TABLE 4.--LEADING-EDGE DISTURBANCE SIZES

\begin{tabular}{|c|c|c|}
\hline $\begin{array}{c}\text { Tape height, } k, \\
\text { in. }\end{array}$ & $\begin{array}{c}\text { Tape height, } k, \\
\mathrm{~mm}\end{array}$ & $k / c$ \\
\hline 0.020 & 0.51 & 0.00028 \\
0.030 & 0.76 & 0.00042 \\
0.040 & 1.02 & 0.00056 \\
0.050 & 1.27 & 0.00069 \\
\hline
\end{tabular}

\subsection{Results and Discussion}

\subsection{Clean Model Aerodynamics}

The aerodynamic characteristics of the clean wing model were measured to confirm the airfoil stall type, show that no flow anomalies existed and document the state of the boundary layer near the airfoil trailing edge. For typical anti-icing fluids testing, procedures were established, and implemented in this research, to simulate an airplane takeoff profile. The angle of attack was set to $-2^{\circ}$ before accelerating the test section airflow from $20 \mathrm{kn}(10.3 \mathrm{~m} / \mathrm{s})$ to $100 \mathrm{kn}(51.4 \mathrm{~m} / \mathrm{s})$ in less than $31 \mathrm{sec}$. In a typical profile, the model was rotated from $\alpha=-2^{\circ}$ to $8^{\circ}$ at a rotation rate of $2.7^{\circ} / \mathrm{sec}$. after the air speed reached $100 \mathrm{kn}$. The model was held at $8^{\circ}$ for $1.5 \mathrm{sec}$ to gather more data at this angle of attack, then the angle was reduced. In other runs, the angle of attack was increased through stall along with other variations in rotation speed and time. This procedure required conditional (or phase) averaging of the data during post-processing to develop lift, drag and pitching moment information versus angle of attack. These results were compared to aerodynamic performance data that were acquired at fixed angle of attack in a pitch-pause mode with one-degree increments in angle of attack. As shown in Figure 4, there was some difference in the maximum lift characteristics depending upon the angle of attack sweep rate. The actual value of $C_{L, \max }$ varied only from 2.20 to 2.24 while $\alpha_{\text {stall }}$ varied from $19.5^{\circ}$ to $20.5^{\circ}$. These differences may be explained in part by unsteady aerodynamic effects. The conditional averaging procedure required for the acquisition of dynamic data can also be affected by the magnitude of the unsteadiness versus the number of samples available to be averaged. Therefore some variation in the dynamic data is expected. Repeat runs in pitchpause mode yielded a higher degree of repeatability in the performance data, particularly at stall. Therefore, all of the data acquired for these aerodynamic characterization experiments were carried out using the pitch-pause mode. 

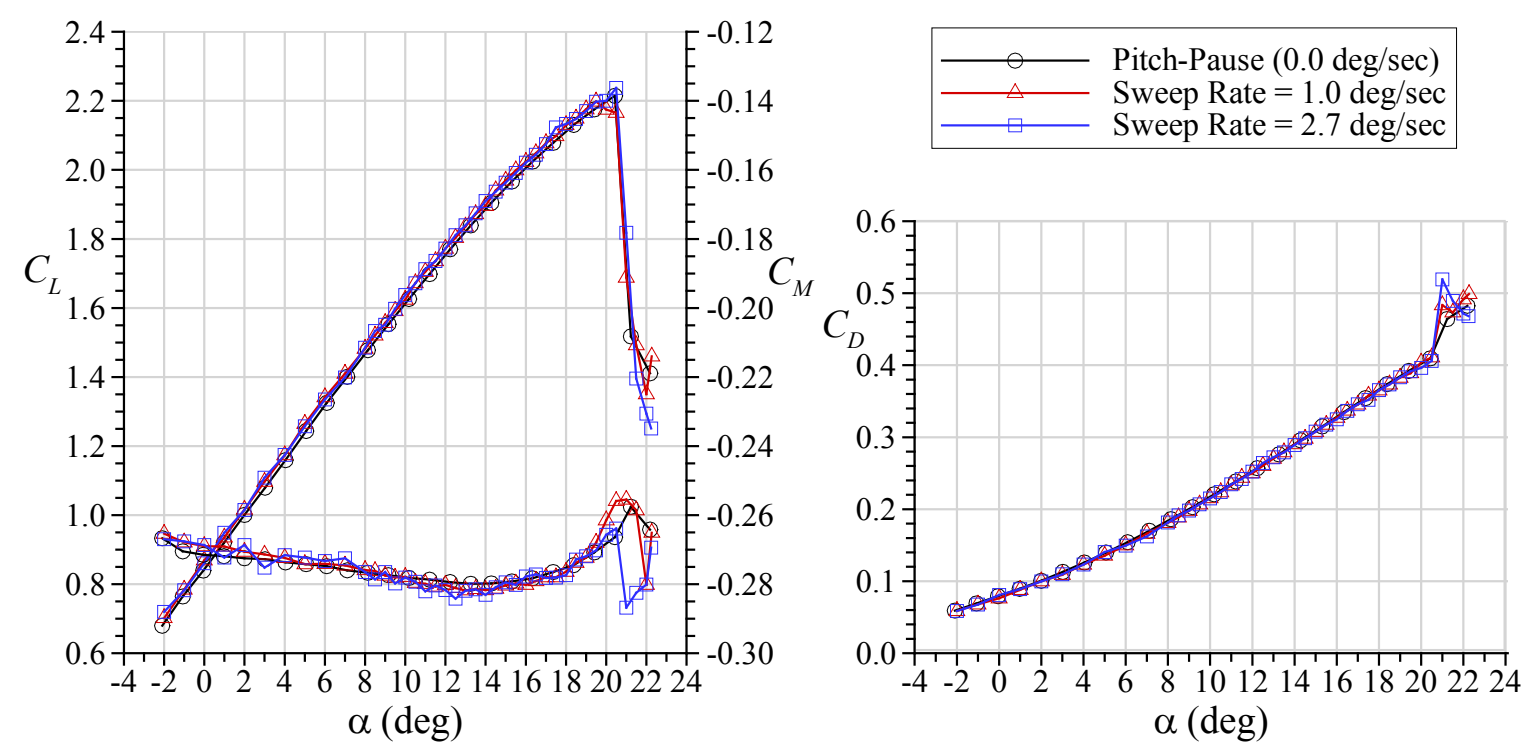

Figure 4.-Effect of angle of attack sweep rate on airfoil aerodynamic performance.

One of the characteristics of the thin, high-performance wing section exhibited in Figure 4 is the sharp decrease in lift coefficient at stall. This behavior is typical of leading-edge stall which has been defined as abrupt flow separation near the leading edge without subsequent reattachment.22 The "abrupt" separation usually results from a small leading-edge laminar separation bubble which "bursts" at stall and causes the sharp decrease in lift (Refs. 22). Flow visualization was conducted to confirm the leading-edge stall type of the airfoil and to determine if there were any adverse effects due to the unique model installation with the relatively small endplates. Surface oil flow visualization indicated that there was a small, leading-edge laminar separation bubble located on the upper surface. This situation is depicted in Figure 5 with the model at $8^{\circ}$ angle of attack. Figure 5 also shows a phenomenological sketch of the flow that was adapted from Tanner (Ref. 23) but has been documented in numerous other references (e.g., Refs. 24 to 27). The separated flow region inside the bubble is clearly visible in the photograph as the thick black line of accumulated surface oil. The boundary-layer reattachment region was located immediately downstream at approximately $x / c=0.05$. Increasing the angle of attack to $18^{\circ}$, which is about two degrees prior to stall, had the effect of moving the laminar separation bubble upstream as depicted in Figure 6. Although very difficult to judge from this photograph the reattachment region is estimated to be at approximately $x / c=0.03$. An additional observation from the flow visualization images in Figure 5 and Figure 6 is that the separation bubble had a very clear 2-D structure across the span of the model which indicates that 2-D flow was maintained on the leading-edge area approaching aerodynamic stall. 

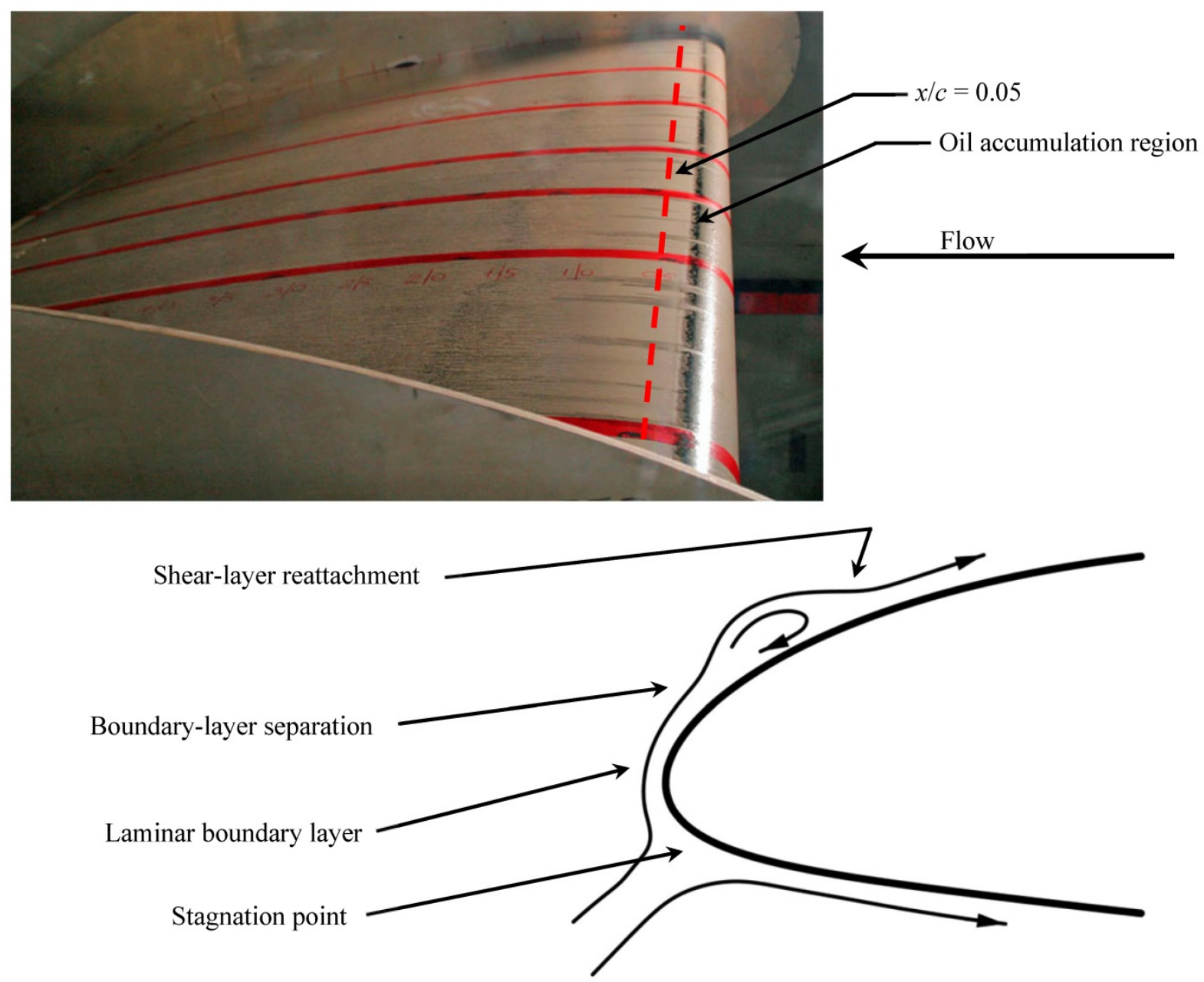

Figure 5.-Photograph of surface-oil flow visualization (top) at $\alpha=8^{\circ}$ and phenomenological sketch of laminar separation bubble flowfield, adapted from Tanner (Ref. 23).

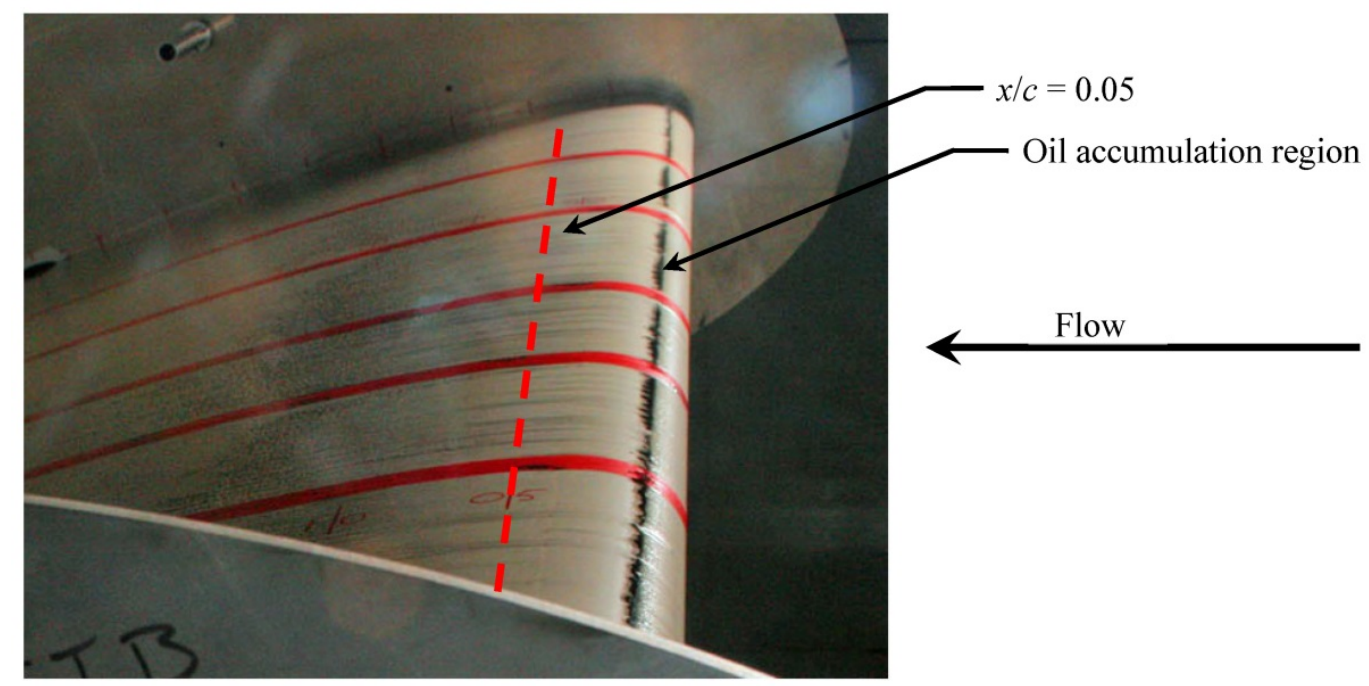

Figure 6.-Photograph of surface-oil flow visualization at $\alpha=18^{\circ}$ 
Verifying the extent of 2-D flow approaching stall was an important part of this work because the influence of the small endplates and large gaps was unknown. Initially, it was expected that the combination of the small endplate size and relatively large gaps between the test-section walls and the model endplates would lead to significant 3-D effects near stall. Additional flow visualization images were acquired for the other portions of the wing model at $\alpha=18^{\circ}$ which was determined to be sufficiently close to the stalling angle to characterize the surface flow. Shown in Figure 7 are surface-oil flow visualization images near the trailing edge of the wing main element extending to the left and right-side endplates. The images show that the boundary-layer remained attached and that the surface flow was highly 2-D, even in areas adjacent to the endplates. These images were also corroborated with images from the thread tufts extended to the left and right sides. The tuft images showed no indication of spanwise flow on the model. Similar results were obtained for flow visualization performed on the flap, depicted in Figure 8. In this case, there were small regions of spanwise flow evident near the endplates. This was attributed to very narrow gaps between the endplates and the flap. These narrow gaps were not sealed as was the main element, to allow for adjustment of the flap angle. The surface-oil flow images near the trailing edge of the flap were somewhat ambiguous, indicating a low-shear flow on the surface. Flow visualization with thread tufts did not indicate flow separation in this region. This was corroborated with boundary-layer pressure rake measurements, discussed in the following paragraph. Overall, the flow visualization results confirmed the leading-edge stall type characterized by a leading-edge laminar separation bubble and very little or no turbulent boundary-layer separation on the main element or flap. Furthermore, the surface flow was remarkably 2-D given the small size of the endplates and large gaps between the endplates and test-section walls.

Boundary-layer velocity profiles were measured near the trailing edge of the main element and flap using the pressure rake shown in Figure 3. Additional measurements were conducted with the rake positioned at $y / b= \pm 0.25$ on the main element trailing edge to quantify potential spanwise variation over the middle 50 percent of the model span. Data were acquired over a large angle of attack range and a subset of the velocity profiles are depicted in Figure 9 for $\alpha=8,14$ and $18^{\circ}$. These profiles illustrate the boundarylayer growth approaching stall. The profiles on the main element were characteristic of a turbulent boundary layer and exhibited minimal differences across the wing span. The velocity profiles on the flap show the classic confluence of the flap boundary-layer and the wake of the main element for a well-designed slotted flap system. Since the confluent boundary-layer thickness exceeded the vertical extent of the pressure rake, the flap velocity profiles could not be normalized by the true edge velocity. Instead the largest velocity measured in the profile (e.g., $z^{\prime}=80 \mathrm{~mm}$ at $\alpha=8$ and $14^{\circ}$ and $z^{\prime}=25 \mathrm{~mm}$ at $\alpha=18^{\circ}$ ) was used to normalize the profiles. The velocity profiles further support the flow visualization results that indicated an absence of boundary-layer separation on the main element and flap trailing edges approaching stall.

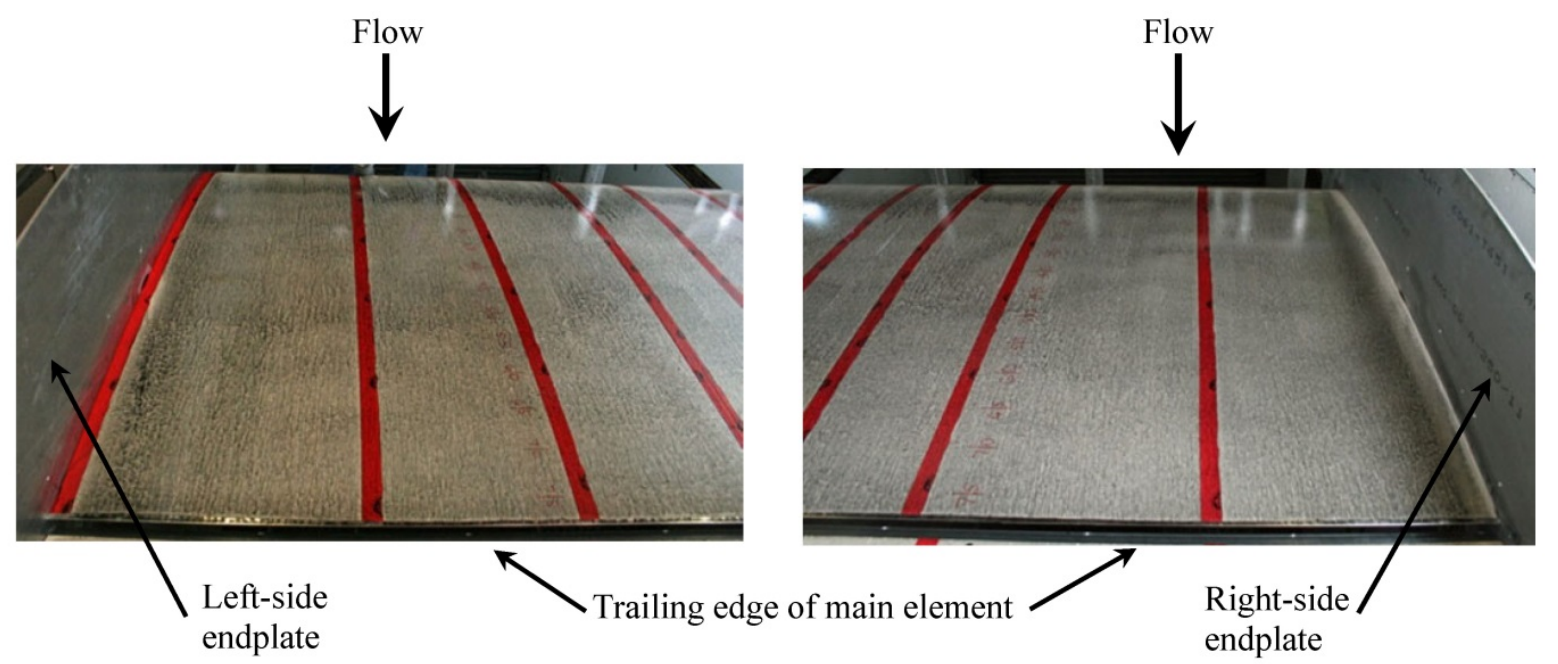

Figure 7.-Photographs of surface-oil flow visualization the left and right sides of the model main element at $\alpha=18^{\circ}$. 


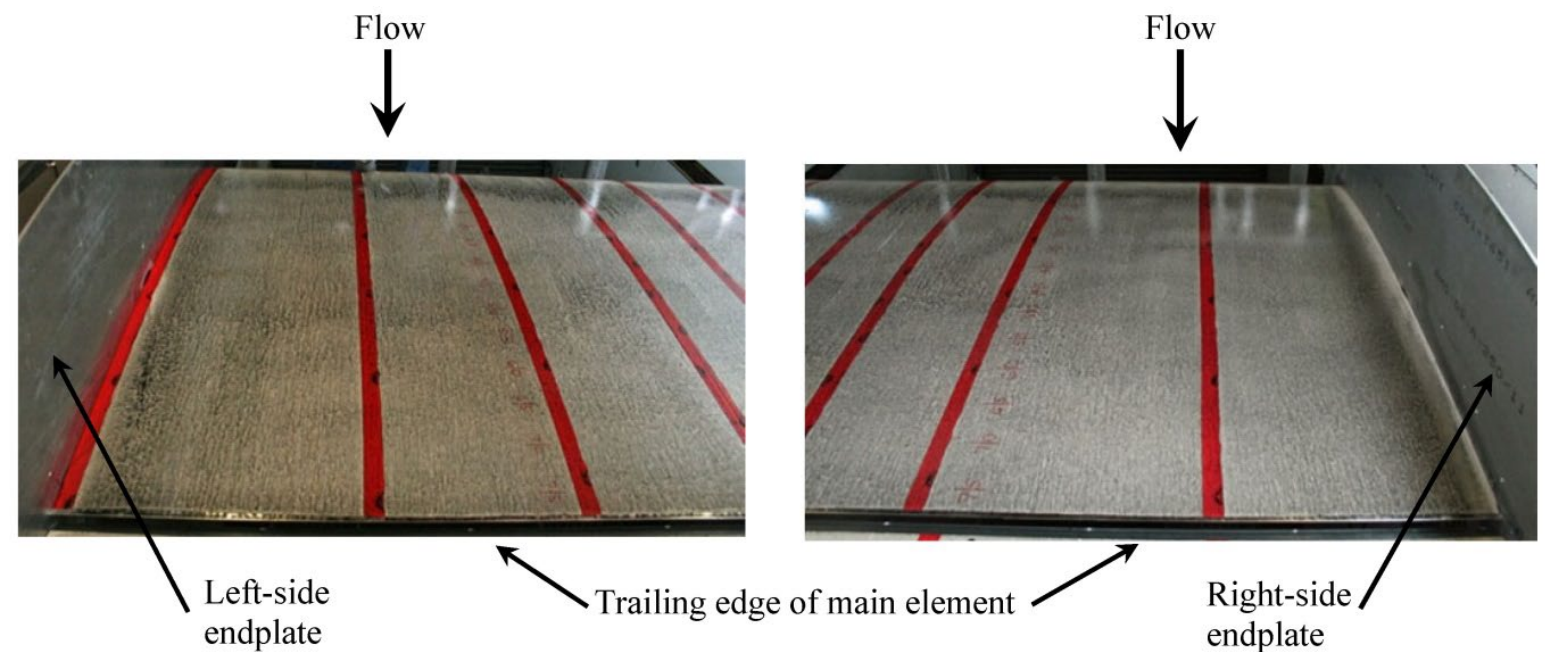

Figure 8.-Photographs of surface-oil flow visualization the left and right sides of the model flap at $\alpha=18^{\circ}$.

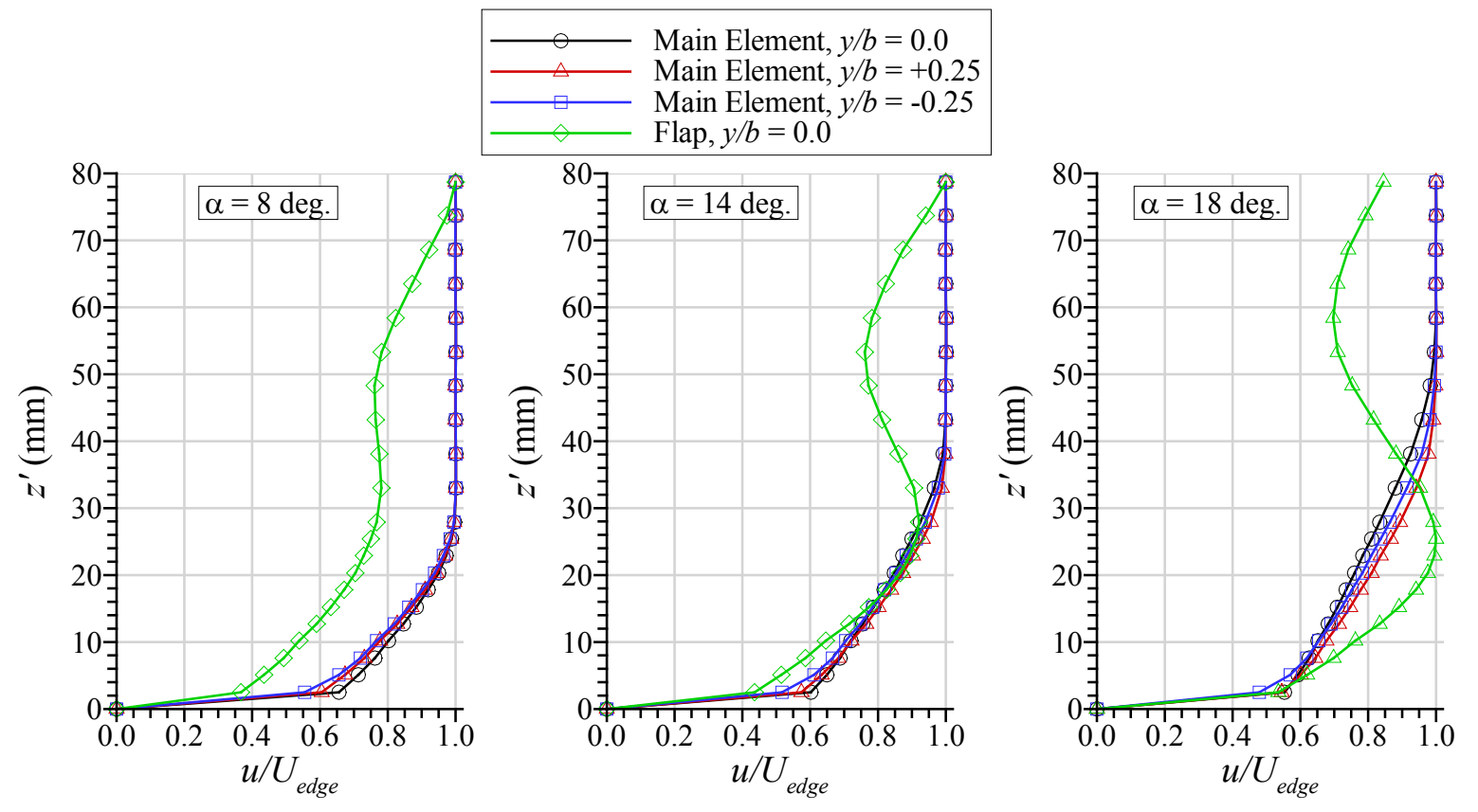

Figure 9.-Comparison of boundary-layer velocity profiles taken at the trailing edge of the main element and flap for three angles of attack.

The velocity profiles were used to calculate the integrated boundary-layer parameters described in Equations (1) to (3) and are plotted in Figure 10. These values could not be calculated for the flap at angles of attack greater than $8^{\circ}$ because the thickness of the confluent boundary layer exceeded the height of the pressure rake as described in the previous paragraph. The displacement and momentum thickness on the main element increased with angle of attack as expected, reflecting the respective increases in boundary-layer thickness and skin-friction drag. These integrated values exhibited more spanwise variation than was observed in the velocity profiles, but this variation is not considered to be significant. The boundary-layer shape factor calculated for the main element decreases with angle of attack thus indicating an increasing resistance to boundary-layer separation at these locations. 

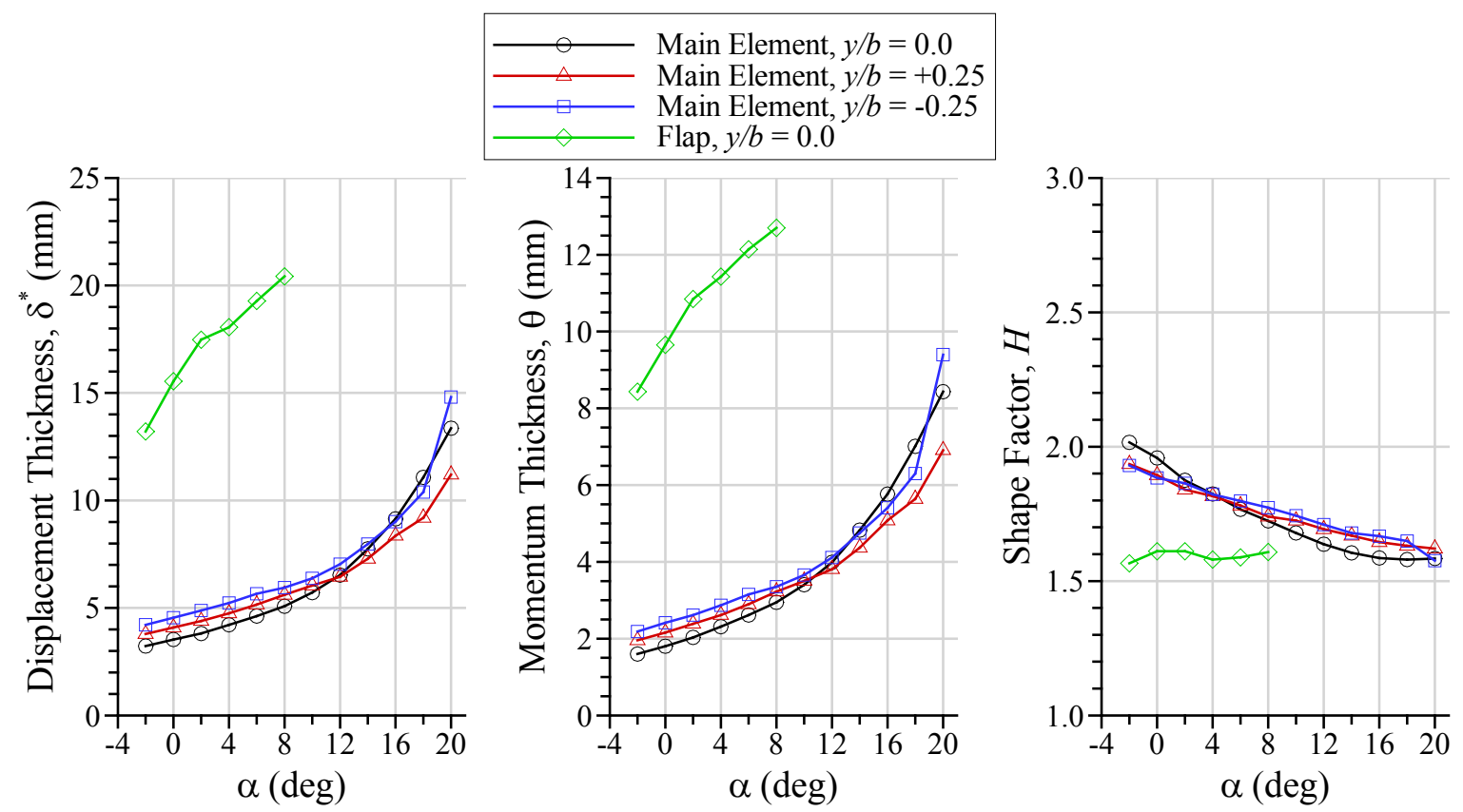

Figure 10.- Variation of integrated boundary-layer parameters with angle of attack at the trailing edge of the main element and flap.

The experiments with the clean, baseline model confirmed the leading-edge stall type of the airfoil including the presence of the laminar separation bubble and minimal or no separation on the trailing edge of the main element or flap. The lack of separation was further confirmed from the evolution of the boundary-layer velocity profiles with increasing angle of attack. Furthermore, the surface flow was found to be 2-D leading up to stall, which is an important observation given the unique installation between the small endplates. Therefore, the baseline aerodynamics of the model showed no anomalies that could adversely affect the evaluation of anti-icing fluids and ice-pellet contamination.

\subsection{Effect of Simulated Leading-Edge Ice Roughness and Upper-Surface Frost}

Experiments were conducted with simulated leading-edge ice roughness and upper-surface frost in order to better understand the aerodynamic origins of the adverse performance effects due to the antiicing fluids and ice-pellet contamination. The effect of varying roughness size on the airfoil performance is shown in Figure 11. Bragg et al. (Ref. 28) describe the aerodynamic effect of leading-edge ice roughness. Even though the ice roughness height tends to be many times larger than the local boundarylayer thickness the scale of separated flow tends to be limited to the immediate vicinity of the individual roughness elements. Therefore there is only a small effect on the inviscid flowfield until the airfoil stalls. These effects are illustrated in Figure 11 where there was little change in the lift-curve slope or zero-lift angle. The chief effects of the roughness were reduced maximum lift coefficient and stalling angle. There was minimal change in the pitching moment characteristics prior to stall. There was no observed change in the drag coefficient prior to stall due to the large contribution of induced drag relative to the profile drag because of the unique model installation between small endplates. A significant increase in profile drag would be expected based upon airfoil test results (Ref. 28). The lift and pitching moment data seem to indicate that the leading-edge stall characteristics of the wing section were preserved even with roughness applied to the leading edge. This is evidenced by the sharp drop in lift after stall (particularly for the $k / c=0.00005$ and 0.00010 roughness) and break in the pitching moment. Such behavior is not uncommon with other leading-edge stall airfoils such as the NACA 23012 (Ref. 29). The magnitude of 
the reduction in maximum lift coefficient range from 20 to 30 percent, which is also lower than values reported for the NACA 23012 airfoil at similar Reynolds numbers (Ref. 29).

These results have been compiled and compared against similar tests from the icing aerodynamics literature. For example, Lynch and Khodadoust (Refs. 30) provided an extensive review of icing aerodynamics and compiled some of the data shown in Figure 12. Plotted is the effect of leading-edge roughness height on loss in maximum lift coefficient. Inspection of the figure shows that the maximum lift degradation measured on the thin, high-performance wing in the PIWT is within the range of many other airfoil studies (Refs. 29, and 31 to 33 This comparison provides further evidence of suitable performance of this wing for anti-icing fluid research.
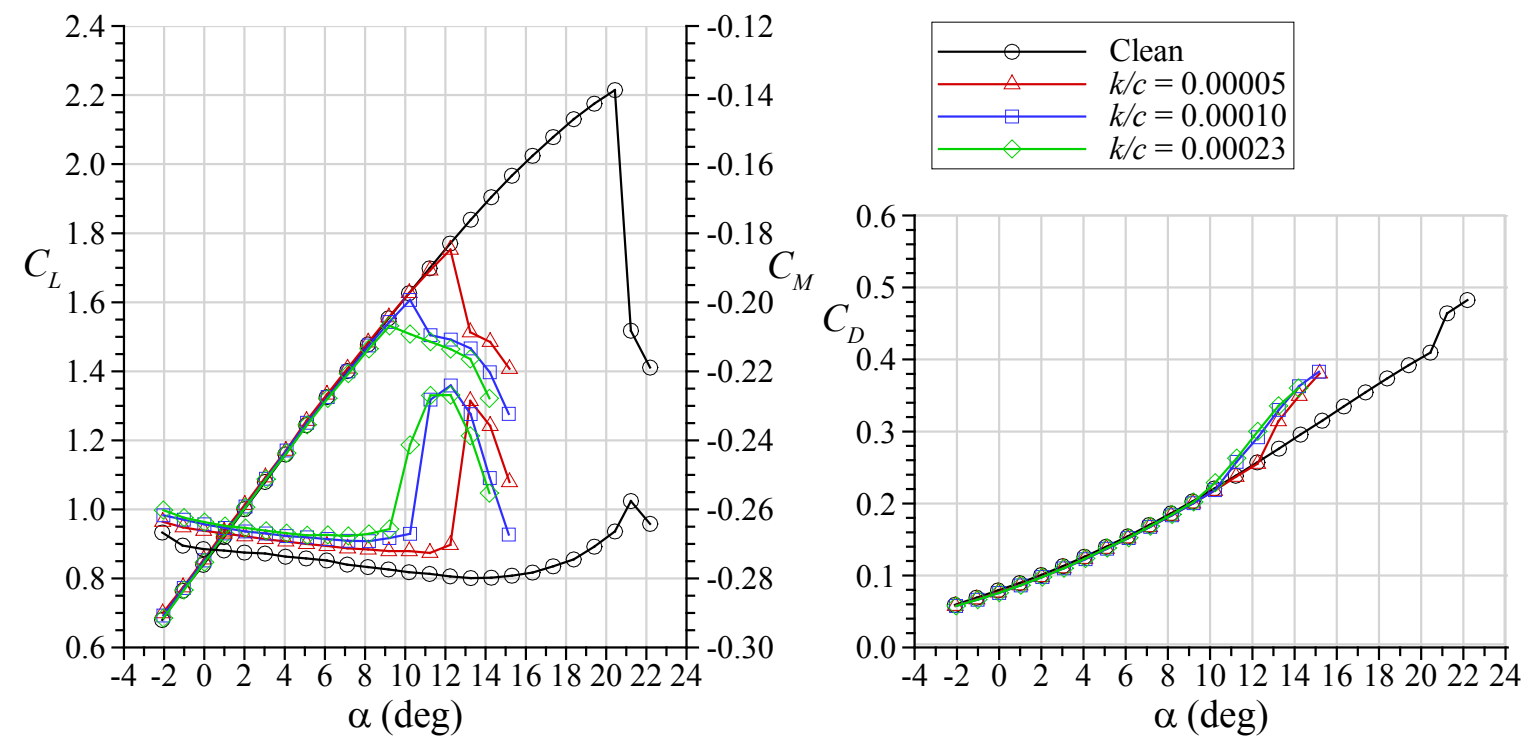

Figure 11.-Effect of sandpaper roughness applied to wing leading edge from $x / c=0.08$ on the lower surface to $x / c=0.05$ on the upper surface.

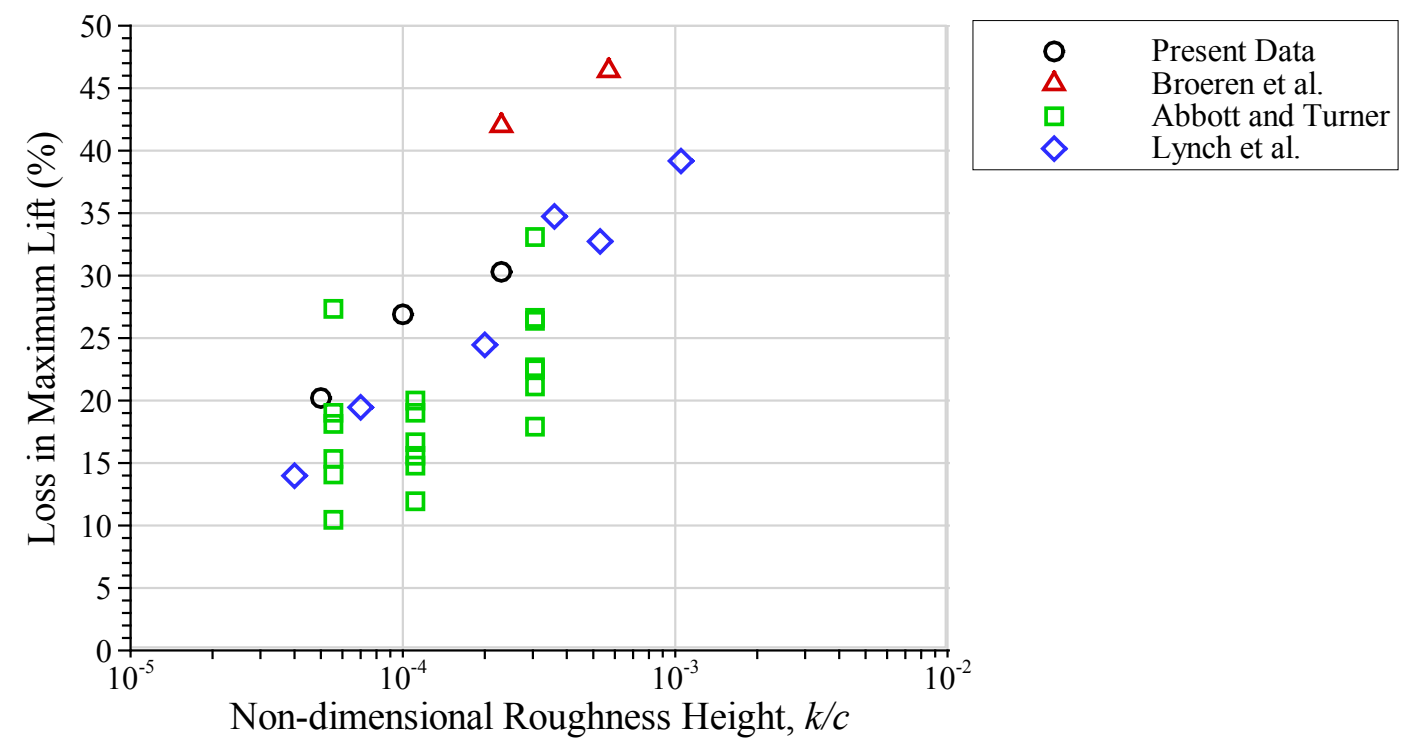

Figure 12.-Effect of leading-edge roughness size on loss of maximum lift; comparison of present data to archival compilation adapted from Lynch and Khodadoust (Ref. 30) with additional data from Broeren et al. (Ref. 29) Abbott and Turner (Ref. 31) and Lynch et al. (Refs. 32 and 33). 

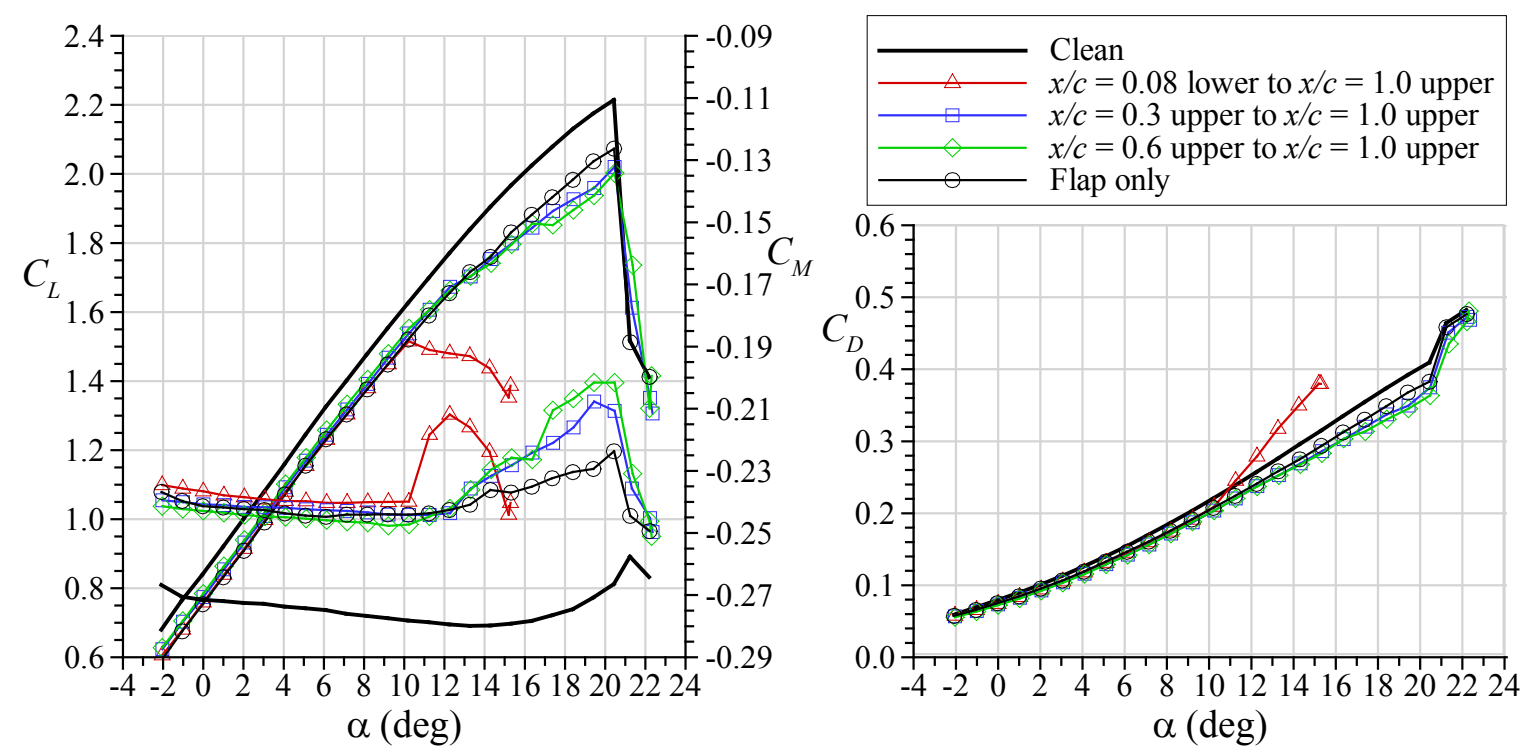

Figure 13.-Effect of chordwise coverage of $k / c=0.00010$ sandpaper roughness applied to the wing upper surface.

A number of studies have been conducted using roughness located on the entire wing upper surface to simulate ground frost conditions (Refs. 15, 17, and 34). A comparison of this effect to roughness located on the leading edge only is shown in Figure 13 for $k / c=0.00010$. The main effects were observed in lift and pitching-moment coefficient. While significant changes in profile drag are expected, they cannot be quantified from the drag coefficient shown in Figure 13 because of the large contribution of induced drag and drag due to the endplates. The shift in both lift and pitching-moment coefficient curves for the entire upper-surface roughness coverage (i.e. $x / c=0.08$ lower to $x / c=1.0$ upper) results from the roughnessinduced thickening of the boundary layer (Refs. 14 and 17). This increase in boundary-layer displacement thickness effectively de-cambered the wing which caused the reduction in lift coefficient and increase in pitching moment coefficient for a given angle of attack (Refs. 14 and 17). For this wing section, the extension of the leading-edge roughness (Figure 11) over the entire upper surface (Figure 13) did not affect the stalling angle which was about $10^{\circ}$ for both cases. This may be due to the strong leading-edge stall tendency of this airfoil. The addition of the $k / c=0.00010$ roughness, even over the entire upper surface, does not appear to have caused significant trailing-edge separation. This assumption is deduced primarily from the pitching-moment behavior, which was sharply increased at stall for the roughness configurations. A more gradual change in pitching moment would be expected if trailing-edge separation were present.

This result was investigated further by systematically removing the upper-surface roughness beginning from the leading edge and working downstream. As shown in Figure 13, the aerodynamic performance tends to be similar for all of the configurations once the roughness is removed from the leading edge. There appears to be a break in the lift and pitching-moment curves at $\alpha \approx 12^{\circ}$ for the $k / c=$ 0.00010 roughness located on the aft 70 percent chord (i.e., $x / c=0.3$ upper to $x / c=1.0$ upper) and aft 40 percent chord (i.e., $x / c=0.6$ upper to $x / c=1.0$ upper). This break may indicate possible trailing-edge separation on the flap. There does not appear to be a similar break for the roughness located on the flap only. In all three of these cases (roughness located on aft 70 percent of chord, 40 percent of chord and flap only), the stalling angles are nearly identical with a small variation in maximum lift coefficient.

The effect of the simulated frost coverage on aerodynamic performance was compared against results from Runyan et al. (Ref. 17) who performed similar experiments on an 9.1 percent scale, 3-D half-plane model of a Boeing 737-200ADV airplane. The experiments were conducted at near operational airspeeds, but the Reynolds number based upon average chord length was only about $1.0 \times 10^{6}$ due to the small model scale. Depicted in Figure 14 are the lift and pitching-moment characteristics plotted in similar form to the 
original Runyan et al. (Ref. 17) data. The general form of the performance effects of the 40, 70 and 100 percent chordwise coverage is similar between the data sets. These similarities are more readily visible in the pitching-moment coefficient variation with lift coefficient. As described earlier in this section, the large chordwise extent of the roughness has the effect of increasing the boundary-layer displacement thickness on the aft section of the wing. The aerodynamic result is a decrease in wing camber and a corresponding increase in pitching moment. There is less of an effect of the roughness on lift coefficient for the 9.1 percent scale B737-200ADV wing which could be due to the 3-D configuration versus the 2-D model configuration for the present tests. In addition, there could be Reynolds number effects for the 9.1 percent scale model data that would minimize the effect of the roughness on lift coefficient.
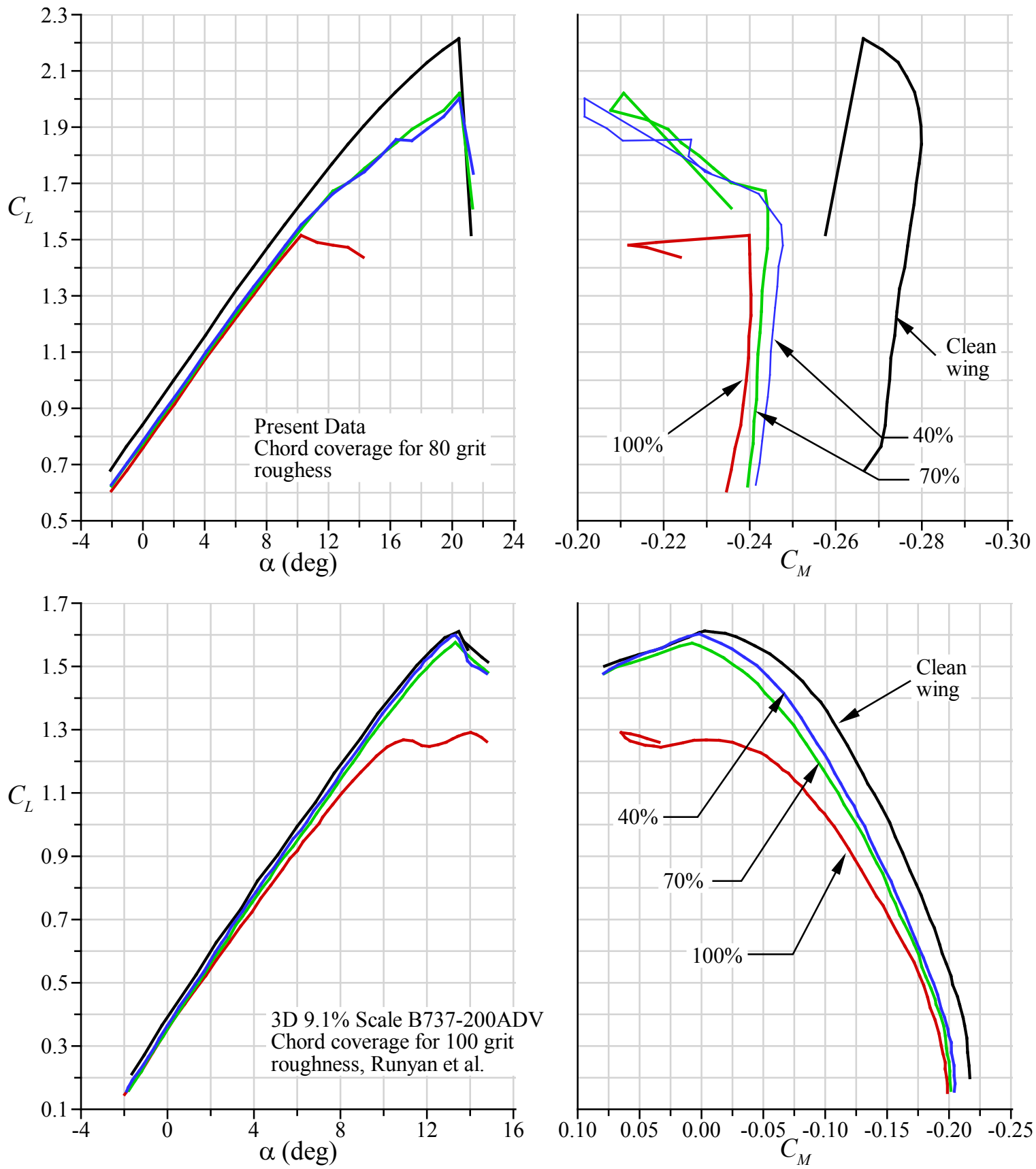

Figure 14.-Comparison of aerodynamic effects of chordwise coverage of sandpaper roughness for present data and data from Runyan et al. (Ref. 17) on 9.1 percent scale 3-D B737-200ADV half-plane model. 
The simulated frost effects were compared to the effects of anti-icing fluid and ice-pellet contamination, also following the method of Runyan et al. (Ref. 17) These results are shown in Figure $15 \mathrm{for}$ the $k / c=$ 0.00010 roughness located on the flap compared to an anti-icing fluid tested at $-5{ }^{\circ} \mathrm{C}$ and the same anti-icing fluid exposed to moderate ice-pellet precipitation at $-8.4^{\circ} \mathrm{C}$. Data for the latter cases (with fluid and contamination) were obtained following the procedure simulating a takeoff acceleration profile and subsequent angle of attack rotation at $2.7 \% \mathrm{sec}$, while the roughness configuration was taken at steady-state conditions in pitch-pause mode. The obvious effect of the simulated takeoff profile is that the fluid/contamination flow off of the wing during the run. This was observed visually and recorded during the experiments. The aerodynamic effect of this is seen in both the lift and pitch-moment variation with angle of attack. The linear portion of the lift curves for the two fluid cases had slightly higher slope than for the roughness configuration. The fluid cases caused a larger aerodynamic penalty relative to the clean, dry wing at lower angle of attack. As the angle of attack was increased, more fluid/contamination flowed off the wing thus reducing the aerodynamic impact. The pitching-moment was affected in an analogous way. For the fluid/contamination cases, the pitching-moment coefficient decreased more than for the roughness configuration as the angle of attack was increased due to the dynamics of the fluid flowing off of the wing. What is perhaps more interesting is the difference in stall behavior between the roughness configuration and the fluid cases. Stall for the latter cases occurred at lower angle of attack and lift coefficient compared to the roughness configuration. Furthermore, there was no clear "break" (or slope change) in the lift curve for the fluid cases. This appears to indicate that stall may be driven by residual fluid and/or contamination located in the leading-edge region as opposed to the contamination on the aft portion of the wing and flap. This is often referred to as a "secondary wave" of fluid and is addressed in Section 3.4.

The data in Figure 15 were compared once again to the Runyan et al. (Ref. 17) results plotted in a common format in Figure 16. The lift coefficient variation with angle of attack shows similar trends between the two data sets. In the Runyan et al. (Ref. 17) data on the 9.1 percent scale B737-200ADV half-plane model, the differences in lift-curve slope between the transitory fluid results and the static roughness configuration are more obvious than in the present data. However, there are very comparable effects on maximum lift coefficient and stalling angle. The trends in pitching-moment coefficient versus lift coefficient are also very comparable between the two data sets. The comparisons shown in Figure 14 and Figure 16 are significant because they illustrate similar trends of fluid effects on aerodynamic performance for two different wing configurations. This provides further evidence suggesting that the present PIWT wing configuration is suitable for the fluid and contamination research.
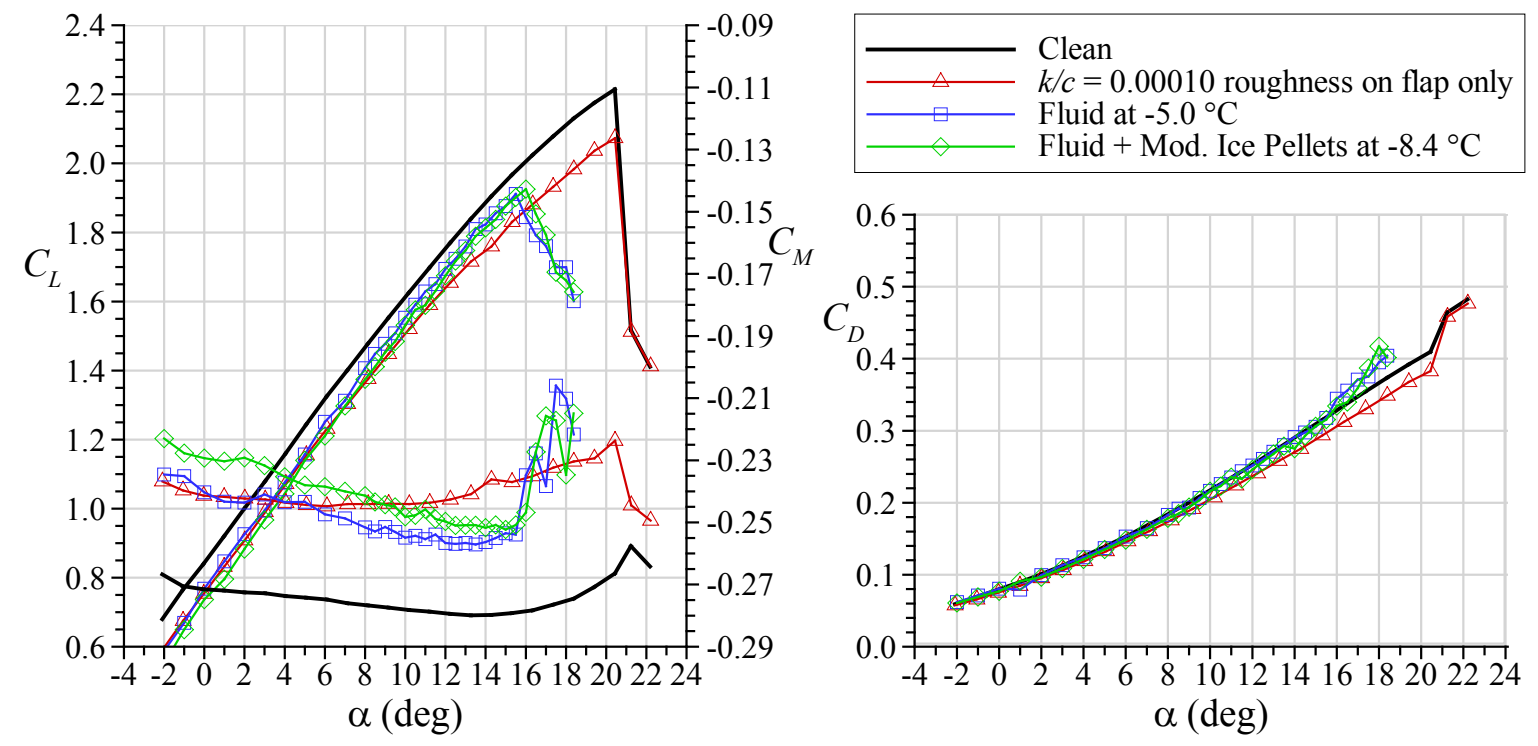

Figure 15.-Comparison of aerodynamic effects of $k / c=0.00010$ sandpaper roughness applied to the airfoil upper surface on the wing flap with fluid and fluid plus ice-pellet contamination. 

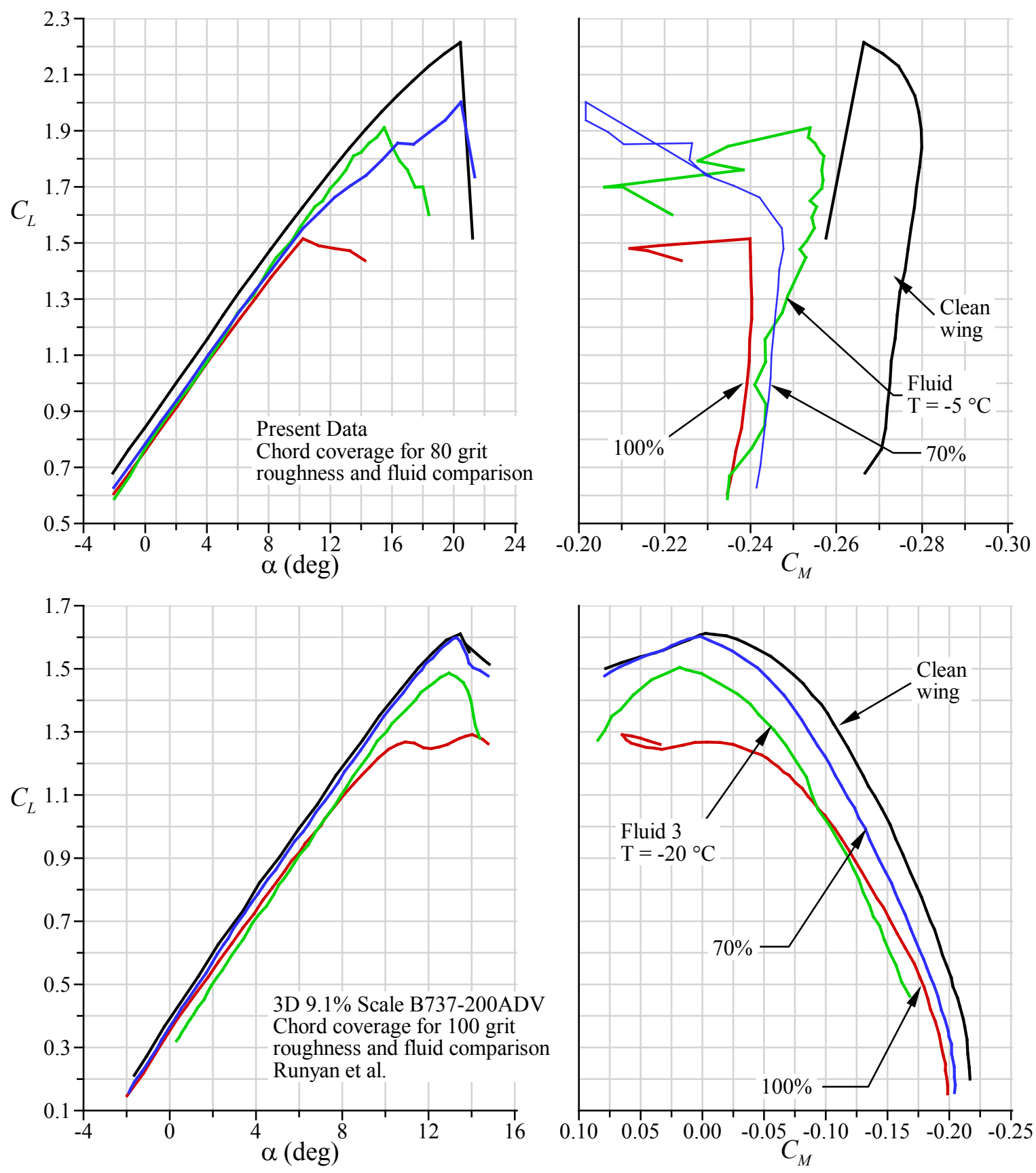

Figure 16.-Comparison of aerodynamic effects of chordwise coverage of sandpaper roughness and fluid for present data and data from Runyan et al. (Ref. 17) on 9.1 percent scale 3-D B737-200ADV half-plane model.

\subsection{Effect of Contamination on the Flap}

A series of experiments were conducted to investigate the aerodynamic performance effects of contamination on the wing flap. Referring back to Figure 15, it was observed that there was a significant difference in stalling angle and maximum lift coefficient between the $k / c=0.00010$ roughness on the flap versus the fluid/contamination configurations. One explanation for this difference is that the fluid/contamination presented a more significant flow disturbance on the flap than the $k / c=0.00010$ roughness. This sensitivity was investigated by applying much larger $k / c=0.00023$ roughness on the flap. The aerodynamic effect is summarized in Figure 17. Consistent with previous results, the data show that 
the larger roughness caused a further thickening of the boundary layer and greater de-cambering of the wing (Refs. 14 and 17). This could also be interpreted as decreasing effectiveness of the flap, or as an effective decrease in the flap deflection. While the larger roughness also caused a significant decrease in maximum lift coefficient relative to the smaller roughness, the stalling angles were nearly identical at $20.4^{\circ}$. This indicates that the reduced stalling angle associated with the fluid/contamination cases in Figure 15 was likely not caused by accumulation of fluid/contamination on the wing flap.

The effect of the roughness on the wing flap on the boundary layer was investigated further. The boundary-layer pressure wake was located near the trailing edge of the main element at the midspan station $(y / b=0.0)$. The velocity profiles in Figure 18 show that the roughness applied to the flap had a small upstream influence on the main element boundary layer. The effect increased with angle of attack
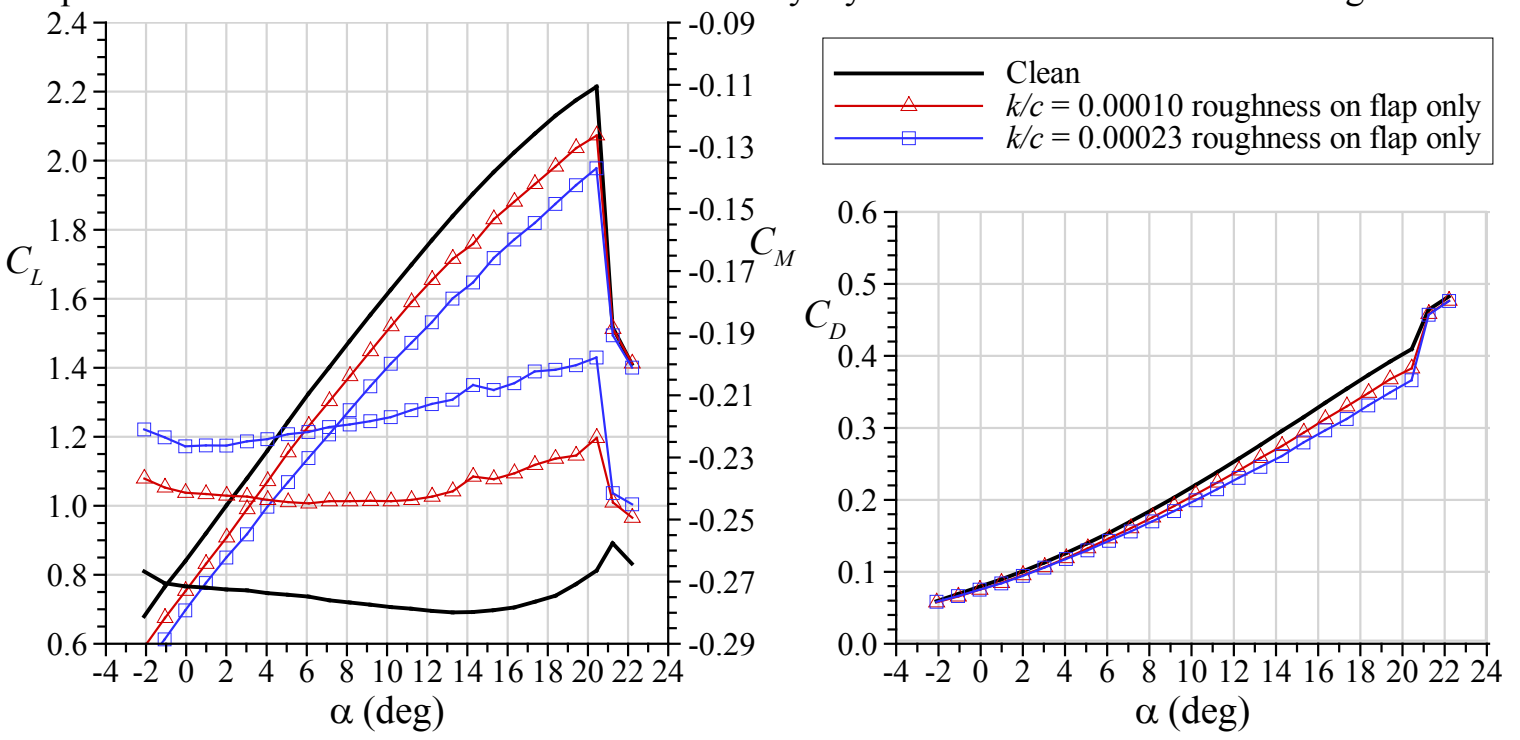

Figure 17.-Aerodynamic sensitivity to roughness size on the wing flap.

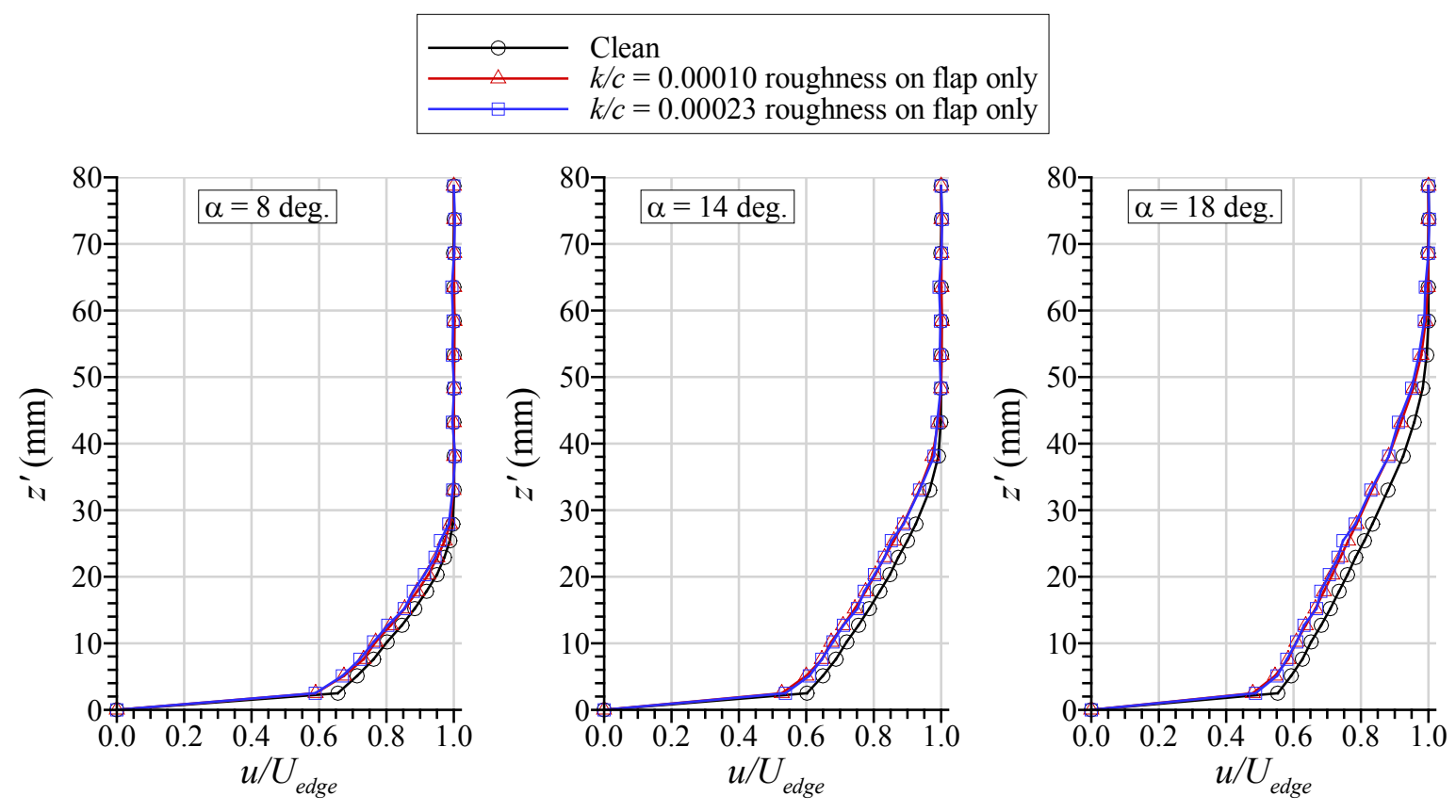

Figure 18.-Effect of roughness applied to wing flap on boundary-layer velocity profiles measured near the trailing edge of the main element at the midspan station $(y / b=0.0)$. 
as indicated in the profiles measured at $\alpha=18^{\circ}$, where the boundary-layers for the roughness configurations were approximately 6 to $8 \mathrm{~mm}$ thicker than for the clean configuration. Larger differences in the boundary-layer profiles were expected given the large differences in corresponding aerodynamic performance shown in Figure 17.

The measurements were repeated with the pressure rake located near the trailing-edge of the flap at the midspan station $(y / b=0.0)$. These profiles, depicted in Figure 19, illustrate the expected significant differences due to the roughness. The boundary layer on the flap was much thicker with the roughness meaning that the rake was not large enough to measure the complete velocity profile. Since the boundarylayer edge velocity was not measured, the data in Figure 19 are normalized by the freestream velocity. The format of the plots is also changed to show the evolution of the boundary-layer profiles with angle of attack for each configuration. For the clean wing, the flap boundary-layer development was clearly seen for $z^{\prime}<30 \mathrm{~mm}$ with the confluence of the main element wake for $z^{\prime}>30 \mathrm{~mm}$. It appears that the edge of the boundary layer was measured for $\alpha=6^{\circ}$ and that the velocity was increasing toward the edge for the other angles of attack for $z^{\prime}>80 \mathrm{~mm}$. With the $k / c=0.00010$ roughness applied to the flap, the velocities for $z^{\prime}<30 \mathrm{~mm}$ are significantly reduced from the clean configuration and the profiles appear to be on the verge of separation near the surface. Farther out in the boundary layer the velocities appear to be increasing toward the edge at $\alpha=6$ and $10^{\circ}$ for $z^{\prime}>80 \mathrm{~mm}$. The velocity profiles for the $k / c=0.00023$ configuration are not significantly different than the $\mathrm{k} / \mathrm{c}=0.00010$ profiles over the range of $z$ ' that could be measured with the pressure rake. Based upon the performance data it was expected that $k / c=0.00023$ profiles would show a thicker boundary-layer than the $k / c=0.00010$ profiles. Some evidence of this is shown at $\alpha=6$ and $10^{\circ}$ for $z^{\prime}>50 \mathrm{~mm}$. Taken together, these data indicate that effect of flow disturbances located on the flap, tend to manifest themselves primarily on the flap itself with limited upstream influence.

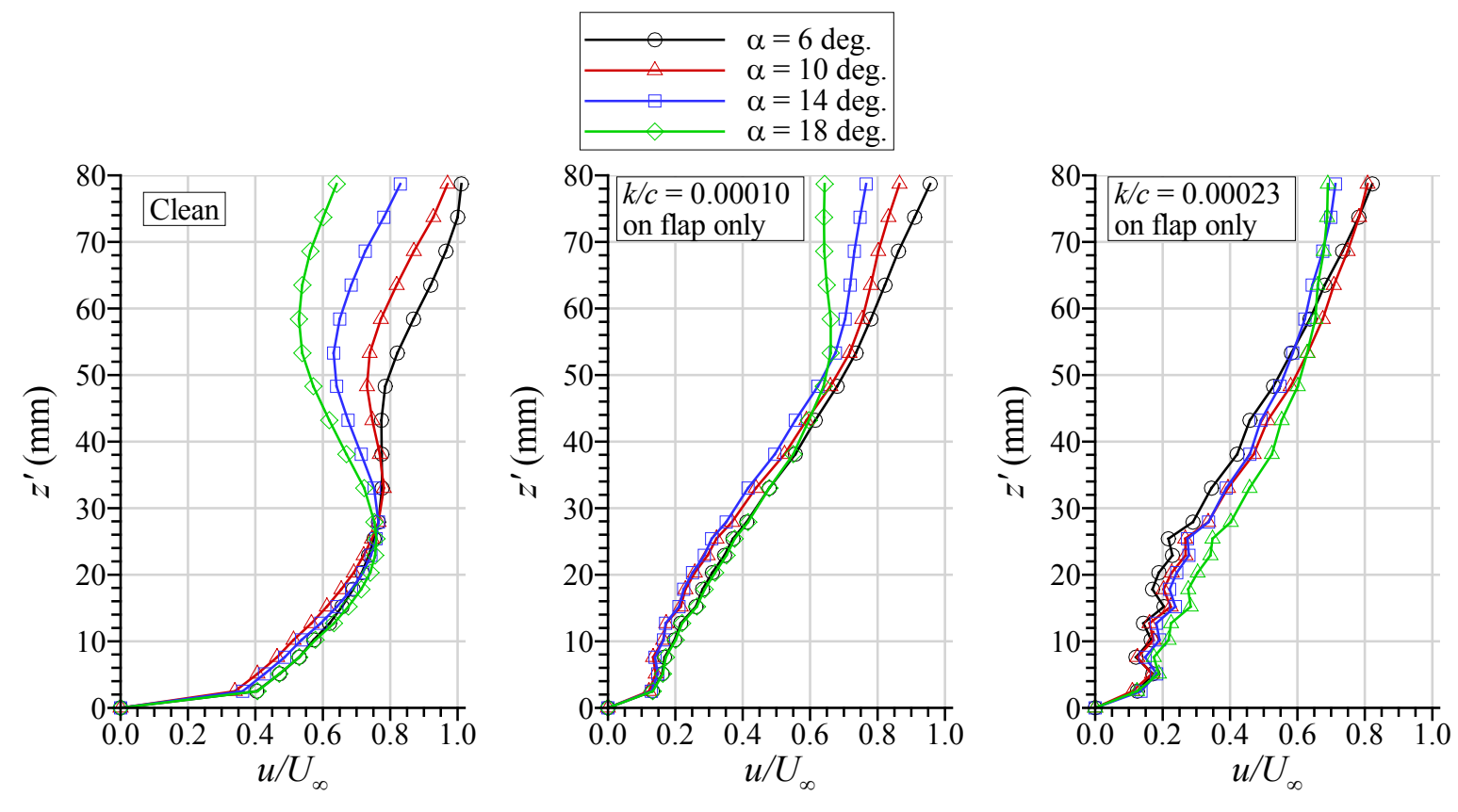

Figure 19.-Effect of roughness applied to wing flap on boundary-layer velocity profiles measured near the trailing edge of the flap at the midspan station $(y / b=0.0)$. 


\subsection{Effect of Leading-Edge Flow Disturbances}

An open question that arose from the discussion of the results in Figure 15 was the origin of the significant difference in stalling angle and maximum lift coefficient between the $k / c=0.00010$ roughness on the flap versus the fluid/contamination configurations. It was concluded in Section 3.3 that this difference in performance was not due to a different level of flow disturbance on the flap. The obvious alternative explanation is that there was some flow disturbance near the wing leading edge for the fluid/contamination cases that caused the lower stalling angle and maximum lift coefficient. As described in Section 3.2, the fluid/contamination was applied to the wing at $\alpha=-2^{\circ}$ The wing was then subjected to a simulated takeoff where the airspeed was increased to $80 \mathrm{kn}$ before the wing was pitched through stall which is a dynamic process.

The transitory nature of anti-icing fluid behavior suggests that some amount of fluid may remain on a wing surface near the leading edge through takeoff. Hill and Zierten (Ref. 14) described this situation based upon their flight tests with a Boeing 737-200ADV airplane. The fluid applied to the wing surface naturally flows around the leading edge to the lower surface due to gravity and surface tension forces prior to the initial take-off acceleration. As the airplane accelerates, the shearing forces near the leading edge are relatively low due to the low angle of attack and low initial velocities during the acceleration. There is some shearing of the fluid as the airplane accelerates resulting in the primary wave of fluid flowing downstream. As the airplane rotates, the shear forces near the leading edge increase significantly and the attachment point moves farther aft on the lower surface. These effects combine to form the secondary wave of fluid that flows around the leading edge and downstream after rotation. While the secondary wave of fluid is generally much thinner than the primary wave, it can have a significant effect on aerodynamic performance because it is located close the wing leading edge at higher angles of attack.

In the present series of tests, this secondary wave was simulated with 2.0 in $(50.8 \mathrm{~mm})$ wide layers of aluminum speed tape with the forward edge placed at $x / c=0.02$ on the upper surface. This location was selected to be upstream of the laminar boundary-layer separation location that was documented with the surface oil flow visualization described in Section 3.1. The effect of increasing tape thickness is illustrated in Figure 20 (cf. Table 4 for dimensional thickness range). Little or no effect on maximum lift and stall angle was observed until the height of the flow disturbance reached $k / c=0.00042$, where there was a significant decrease in stalling angle and maximum lift coefficient. Incrementally increasing the disturbance height had no further adverse effect on the stalling characteristics up to $k / c=0.00069$. The range of maximum lift coefficient was 1.91 to 1.95 at $\alpha_{\text {stall }}=15.3^{\circ}$ for the $k / c=0.00042$ to 0.00069 cases. This compares to a range of $C_{L, \max }=1.91$ to 1.93 and $\alpha_{\text {stall }}=15.5$ to $16.0^{\circ}$ for the fluid and fluid with moderate ice pellets cases in Figure 15. The fact that these values are nearly identical strongly suggests that the reductions in maximum lift coefficient and stalling angle for the fluid/contamination cases were at least partially due to secondary wave effects.

Additional fluid tests were performed using a modified ramp and rotation procedure to isolate secondary wave effects from the overall fluid effects. Anti-icing fluid was applied to the wing using the standard procedures. The airspeed was accelerated to $80 \mathrm{kn}$ with the wing at $\alpha=-2^{\circ}$ and then stopped to achieve fluid distribution on the wing that typically occurs prior to rotation. Fluid was then removed from the upper and lower surface of the wing aft of $x / c=0.17$. In other tests, fluid was removed from the upper and lower surface separately. The airspeed was then accelerated to $80 \mathrm{kn}$ followed by the wing rotation from $\alpha=-2^{\circ}$ to $22^{\circ}$. Additional tests were performed where fluid was manually applied to the wing upper surface upstream of $x / c=0.17$ (identified as "Wing Section A") and to the wing lower surface upstream of $x / c=0.17$ (identified as "Wing Section C"). The resulting aerodynamic effects are summarized in Figure 21. The lift and pitching-moment data show only minor deviation from the clean wing values for angles of attack less than $12^{\circ}$. This result is expected since in all cases there was no fluid on the wing aft of $x / c=0.17$ and therefore minimal effect on the downstream boundary layer. This result is similar to the static simulation tests with leading-edge roughness (Figure 11) and aluminum speed tape layers (Figure 20). Also similar is the effect on the stall angle and maximum lift coefficient that were both significantly reduced from the clean wing values. The lowest values of $\alpha_{\text {stall }}$ and $C_{L, \max }$ in Figure 21 occurred when the fluid was manually 
applied to the wing leading edge on the lower surface (Wing Section C). Fluid located in this region was likely directed toward the upper surface by the stagnation point moving downstream as the wing was pitched from $\alpha=-2^{\circ}$ to $22^{\circ}$. This is exactly the scenario described by Hill and Zierten (Ref. 14) as a secondary wave. The values of $\alpha_{\text {stall }}$ and $C_{L, \max }$ for the fluid manually applied to Wing Section C configuration agree very well with the simulated secondary wave results presented in Figure 20 for $k / c \geq$ 0.00042. Returning to Figure 21, the next highest values of $\alpha_{\text {stall }}$ and $C_{L, \max }$ are for the fluid removed aft of $x / c=0.17$ after ramp. This configuration likely had less total fluid in the leading edge region, but fluid still remained on the lower surface after the ramp. When fluid was manually applied only to the upper-surface, leading-edge area (Wing Section A), the values of $\alpha_{\text {stall }}$ and $C_{L, \max }$ were the highest. There was still a significant performance penalty due to fluid in this location. These fluid test results were consistent with the results simulating the secondary wave. Taken together, it was concluded that the changes in stalling angle due to the fluid and fluid plus contamination were at least partially due to secondary wave effects.
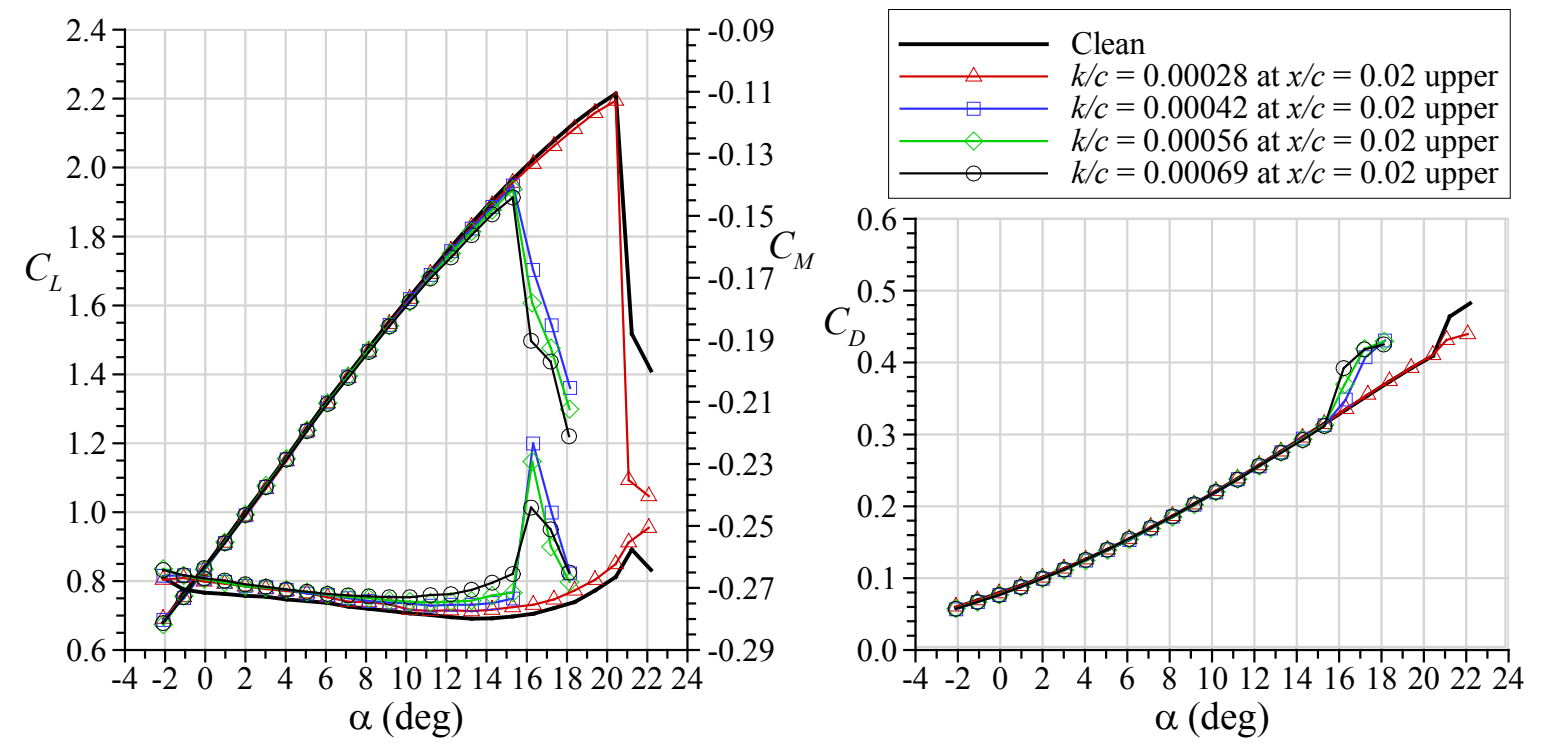

Figure 20.-Effect of flow disturbances near leading edge of wing simulating fluid secondary wave.
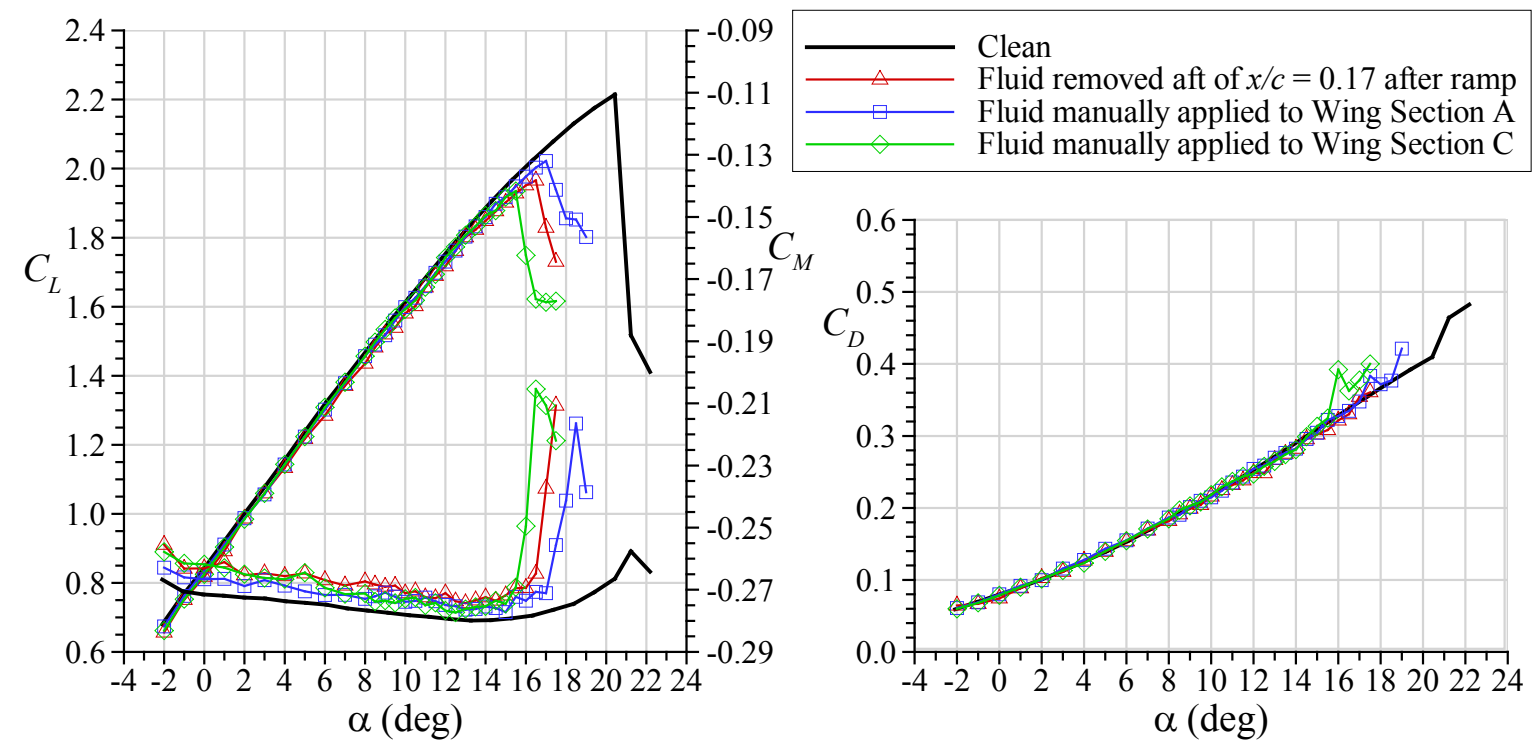

Figure 21.-Comparison of secondary wave effects from fluid tests. 
Another factor that may have influenced the effect of the secondary wave was the laminar separation bubble discussed in Section 3.1. It is possible that this separation bubble could form with fluid on the surface as the wing is rotated through stall. The formation of the separation bubble would further promote accumulation of fluid in a critical location near the wing leading edge. This would increase the height of the secondary wave and contribute to the observed reduction in maximum lift and stalling angle for fluid/contamination cases such as in Figure 15. This phenomenon appeared to occur in a small subset of the photographic documentation of the fluid tests.

\subsection{Summary and Conclusion}

The FAA has worked with Transport Canada and others to develop allowance times for aircraft operating in ice-pellet precipitation. Wind-tunnel testing has been carried out to better understand the flowoff characteristics and resulting aerodynamic effects of anti-icing fluids contaminated with ice pellets. The objective of this paper is to characterize the aerodynamic behavior of the thin, highperformance wing that is important to understanding the adverse aerodynamic effects of anti-icing fluids and ice-pellet contamination. All experiments were carried out at the NRC PIWT using the $6 \mathrm{ft}(1.82 \mathrm{~m})$ chord thin, high-performance wing section. The wing section had a span of $7.9 \mathrm{ft}(2.6 \mathrm{~m})$ and had a single-element, slotted flap fixed at $20^{\circ}$ for these experiments. Aerodynamic performance data, boundarylayer surveys and flow visualization were conducted at a Reynolds number of approximately $6.0 \times 10^{6}$ and a Mach number of 0.12 .

The experiments with the clean, baseline model confirmed the leading-edge stall type of the airfoil including the presence of the laminar separation bubble and minimal or no separation on the trailing edge of the main element or flap. The lack of separation was further confirmed from the evolution of the boundary-layer velocity profiles with increasing angle of attack. Furthermore, the surface flow was found to be 2-D leading up to stall, which is an important observation given the unique installation between the small endplates. The evolution of the boundary-layer velocity profiles with angle of attack also indicated the lack of potential separation at the trailing edge of the wing main element and flap.

The effect of simulated leading-edge ice roughness on maximum lift coefficient and stalling angle was large, but very comparable to archival data found in the technical literature. Further tests also showed that the aerodynamic effect of the anti-icing fluids (and fluid with ice-pellet contamination) were similar to various chordwise coverage of simulated frost. Experiments were also conducted with two different roughness $(k / c=0.0001$ and 0.00023$)$ and sizes applied to the flap. The larger roughness size caused a slightly lower maximum lift coefficient but at the same stall angle as for the smaller roughness size. Boundary-layer surveys near the trailing edge of the main element showed that the roughness applied to the flap had a small upstream influence on the main element boundary layer. Overall, these aerodynamic data indicated that the primary aerodynamic effect of the anti-icing fluid (and fluid with contamination) was essentially a de-cambering of the wing due to increased boundary-layer displacement thickness on downstream portions of the wing including the flap.

Tests were also conducted to investigate effects of a secondary fluid wave that forms as the wing is rotated in the simulated takeoff profile. Layers of aluminum speed tape were applied to the upper surface of the wing at $x / c=0.02$ to simulate a secondary wave of fluid. It was found that a height of $k / c=0.00042$ to 0.00069 resulted in maximum lift coefficients ranging from 1.91 to 1.95 compared to the clean wing value of 2.2. Correspondingly, the stall angle was reduced to $15.3^{\circ}$ for all cases compared to the clean value of $20^{\circ}$. Tests were also conducted with anti-icing fluids using modified procedures to isolate the effects of the secondary wave. These tests resulted in maximum lift coefficients ranging from 1.94 to 2.02 and stall angles ranging from $15.5^{\circ}$ to $17.0^{\circ}$. Based upon the comparison of these results it was concluded that secondary wave effects could have a significant impact on the maximum lift coefficient and stall angle for anti-icing fluid (and fluid with contamination) tests on the thin, high-performance wing.

This aerodynamic characterization of the thin, high-performance wing in the NRC PIWT has yielded important information about the suitability of this model for anti-icing fluid and ice-pellet contamination testing. The clean baseline aerodynamics of the model were consistent with expected 2-D aerodynamics 
and showed no anomalies that could adversely affect the evaluation of anti-icing fluids and ice-pellet contamination. Tests conducted with roughness and leading-edge flow disturbances helped to explain the aerodynamic impact of the anti-icing fluids and contamination. In the linear portion of the lift curve, the primary aerodynamic effect is the thickening of the downstream boundary layer due to the accumulation of fluid and contamination. This causes a reduction in lift coefficient and increase in pitching moment due to an effective de-cambering of the wing. The stalling characteristics of the wing with fluid and contamination appear to be driven at least partially by the effects of a secondary wave of fluid that forms near the leading edge as the wing is rotated in the simulated takeoff profile. These results have provided a much more complete understanding of the adverse aerodynamic effects of anti-icing fluids and ice-pellet

contamination on this wing. This is important since these results are used, in part, to develop the ice-pellet allowance times that are applicable to many different airplanes.

\section{References}

1. Cortinas, J.V., Jr., Bernstein, B.C., Robbins, C.C., and Strapp, J.W., “An Analysis of Freezing Rain, Freezing Drizzle, and Ice Pellets across the United States and Canada: 1976-90," Weather and Forecasting, Vol. 19, April 2004, pp. 377-390.

2. FAA Notice N 8000.308, "Reevaluation of Deicing/Anti-icing Programs," Oct. 5, 2005.

3. FAA Notice N 8000.309, "Dispatching During Precipitation Conditions of Ice Pellets, Snow Pellets, or Other Icing Events for which no Hold Over Times Exist," Oct. 5, 2005.

4. FAA Notice N 8000.313, "Parts 121 and 135 Operations Specification for Deicing/Anti-Icing, Operations in Ice Pellets without Deice/Anti-Ice Fluids," Oct. 31, 2005.

5. FAA Notice N 8000.329, "FAA-Approved Deicing Program Updates, Winter 2006-2007," Oct. 27 , 2006.

6. Broeren, A.P., and Riley, J.T., "Review of the Aerodynamic Acceptance Test and Application to Anti-Icing Fluids Testing in the NRC Propulsion and Icing Wind Tunnel," NASA TM-2012-216014 and DOT/FAA/TC-12/32, Aug. 2012.

7. Broeren, A.P., and Riley, J.T., "Scaling of Lift Degradation Due to Anti-Icing Fluids Based Upon the Aerodynamic Acceptance Test," AIAA Paper 2012-2800, also NASA TM-2012-217701.

8. FAA Notice N 8900.19, "Guidance and Procedures for Dispatching During Ice Pellet and in Heavy Snow Conditions and Evaluating Pilot Assessment of Precipitation Intensity," Sept. 20, 2007.

9. FAA Notice N 8900.22, "FAA-Approved Deicing Program Updates, Winter 2007-2008," Oct. 12, 2007.

10. FAA Notice N 8900.98, “FAA-Approved Deicing Program Updates, Winter 2009-2010,” Oct. 30, 2008.

11. Huang, X.Z., Byers, B.B., D’Avirro, J., and Ruggi, M., "Icing Wind-Tunnel Tests on a Contaminated Full-Scale Wing-Model at Takeoff Conditions," AIAA Paper 2008-6417, Aug. 2008.

12. Clark, C. and MacMaster, M., "Icing Wind Tunnel Tests of a Contaminated Supercritical Anti-Iced Wing Section during Simulated Take-off," AIAA Paper 2011-1101, Jan. 2011.

13. FAA Notice N 8900.167, “FAA-Approved Deicing Program Updates, Winter 2011-2012,” Aug. 29, 2011.

14. Hill, E.G., and Zierten, T.A., "Aerodynamic Effects of Aircraft Ground Deicing/Anti-Icing Fluids," Journal of Aircraft, Vol. 30, No. 1, Jan.-Feb., 1993.

15. Hill, E.G., "Airplane Performance and Other Considerations Related to Airplane Icing While on the Ground," Airplane Deicing Seminar, Aircraft Technology Division, Danish Engineering Society, Feb. 1993.

16. Hill, E.G., and Zierten, T.A., "Aerodynamic Acceptance Test for Aircraft Ground Deicing/Anti-icing Fluids," Boeing Document No. D6-55573, Mar. 1992.

17. Runyan, L.J., Zierten, T.A., Hill, E.G., and Addy, H.E., Jr., "Lewis Icing Research Tunnel Test of the Aerodynamic Effects of Aircraft Ground Deicing/Anti-Icing Fluids," NASA TP-3238, Aug. 1992. 
18. SAE Aerospace Standard, "Standard Test Method for Aerodynamic Acceptance of SAE AMS 1424 and SAE AMS 1428 Aircraft Deicing/Anti-icing Fluids," AS5900 Rev. A, May 2003.

19 Rae, W.H., Jr., and Pope, A. Low-Speed Wind Tunnel Testing, $2^{\text {nd }}$ Ed. John Wiley \& Sons, New York, 1984, pp. 344-362.

20. Clark, C. and MacMaster, M., "Icing Wind Tunnel Tests of a Contaminated Supercritical Anti-iced Wing Section During Simulated Take-off (Phase 2)," NRC-CNRC Report No. LTR-AL-2011-0019, Feb. 22, 2011.

21. Clark, C. and MacMaster, M., "Icing Wind Tunnel Tests of a Contaminated Supercritical Anti-iced Wing Section During Simulated Take-off -Phase 2," AIAA Paper 2012-2799, June 2012.

22. McCullough, G.B., and Gault, D.E., "Examples of Three Representative Types of Airfoil-Section Stall at Low Speed," NACA TN 2502, Sept. 1951.

23. Tanner, C.E., "The Effect of Wing Leading Edge Contamination on the Stall Characteristics of Aircraft," SAE Paper 2007-01-3286, Sept. 2007.

24. Crabtree, L.F., "Effects of Leading-Edge Separation in Thin Wings in Two-Dimensional Incompressible Flow," Journal of the Aeronautical Sciences, Vol. 24, No. 8, Aug. 1957, pp. 597-604.

25. Tani, I., "Low-Speed Flows Involving Separation Bubbles," Progress in Aeronautical Sciences, Vol. 5, 1964, pp. 70-103.

26. Horton, H.P., "Laminar Separation Bubbles in Two and Three-Dimensional Incompressible Flow," Ph.D. Dissertation, Univ. of London, 1968.

27. Arena, A.V., and Mueller, T.J., "Laminar Separation, Transition, and Turbulent Reattachment Near the Leading Edge of Airfoils," AIAA Journal, Vol. 18, No. 7, July 1980, pp. 747-753.

28. Bragg, M.B., Broeren, A.P., and Blumenthal, L.A., "Iced-Airfoil Aerodynamics," Progress in Aerospace Sciences, Vol. 41, No. 5, July 2005, pp. 323-418.

29. Broeren, A.P., Bragg, M.B., and Addy, H.E., Jr., "Effect of Intercycle Ice Accretions on Airfoil Performance," Journal of Aircraft, Vol. 41, No. 1, Jan.-Feb. 2004, pp. 165-174.

30. Lynch, F.T., and Khodadoust, A., "Effects of Ice Accretions on Aircraft Aerodynamics," Progress in Aerospace Sciences, Vol. 37, No. 8, Nov. 2001, pp. 669-767.

31. Abbott, F.T., Jr. and Turner, H.R., Jr., "The Effects of Roughness at High Reynolds Numbers on the Lift and Drag Characteristics of Three Thick Airfoils," NACA ACR No. L4H21, 1944 (Wartime Report No. L-46).

32. Lynch, F.T., Valarezo, W.O., and McGhee, R.J., "The Adverse Aerodynamic Impact of Very Small Leading Edge Ice (Roughness) Buildups on Wings and Tails," AGARD-CP-496, Paper 12, 1991.

33. Valarezo, W.O., Lynch, F.T., and McGhee, R.J., "Aerodynamic Performance Effects Due to Small Leading Edge Ice (Roughness) Buildups on Wings and Tails," Journal of Aircraft, Vol. 30, No. 6, Nov. 1993, pp. 807-812.

34. Van Hengst, J., Gent, R., Hammond, D., Seubert, R., and Wagner, B., "Ice Accretion and Its Effects on Aircraft," in Ice Accretion Simulation, AGARD AR-344, Paper 3, Dec. 1997. 

